\title{
La medición de la creatividad \\ en destinos urbano-culturales españoles
}

Measuring creativity in urban-cultural Spanish destinations

\author{
Juan Ignacio Pulido-Fernández \\ jipulido@ujaen.es \\ Laboratorio de Análisis e Innovación Turística (LAInnTUR) \\ Universidad de Jaén (España)
}

\section{José Antonio García Suárez}

jagsuarez@gmail.com

Fundación Ciudades Medias del Centro de Andalucía (España)

\author{
Jairo Casado-Montilla \\ jcasado@ujaen.es \\ Laboratorio de Análisis e Innovación Turística (LAInnTUR) \\ Universidad de Jaén (España)

\section{Beatriz Rodríguez-Díaz} \\ brodriguez@uma.es \\ Departamento de Economía Aplicada (Matemáticas) \\ Universidad de Málaga (España)
}




\title{
Resumen
}

Este artículo propone una metodología para la medición del peso específico de la creatividad en los destinos turísticos urbano-culturales. Para ello, recurre al empleo de un índice sintético agregado basado en el DP2 (distancia al peor). Dicho índice, denominado Creacity, aplicado a las ciudades turísticas culturales españolas, permite conocer cuán creativos son estos sistemas locales a través de tres áreas: la espacial, ambiental e institucional. A partir de los indicadores generales y parciales, establece matrices creativas de cada una de las áreas estudiadas, determinando las ventajas y desventajas creativas de los sistemas analizados. La selección de las distintas variables que componen el Creacity se obtiene del análisis de la literatura científica, que parte de un itinerario sobre la epistemología del pensamiento divergente, abordando la idea de ciudad creativa y su adaptación al turismo. Siendo el índice obtenido refrendado por un panel de expertos, a través de un Delphi. Los resultados ponen de manifiesto la importancia de las clases creativas y la existencia de un ambiente de tolerancia, calidad de vida y participación ciudadana en el que se ubican espacios culturales y creativos que fomentan el desarrollo de la creatividad.

Palabras clave: creatividad; turismo; destinos urbano-culturales; DP2; Creacity.

\begin{abstract}
This article proposes a methodology which measures the creativity weight in urban cultural tourism destinations. For this purpose, in this work an aggregated synthetic index is employed, based on DP2 distance index. This index, called Creacity, when applied to tourism cultural cities, allows knowing how creative these local systems are through three main areas: spatial, environmental and institutional. Stemming from general and partial indicators, some creative matrix are established for each studied area, what determine the creative advantages and disadvantages of the analyzed systems. The choice of the different variables that compose Creacity is obtained from the analysis of the divergent thought, addressing the idea of creative city and its adaptation to tourism. The index has been countersigned by a panel of experts through the Delphi method. The results expose the importance of creative classes and the existence of an environment of tolerance, quality of life and civic participation where cultural and creative spaces are located to foster the creativity development.
\end{abstract}

Key words: creativity; tourism; urban-cultural destinations; DP2; Creacity. 


\section{Introducción}

La gestión turística de las ciudades supone uno de los retos más complejos a los que hacen frente los gobiernos, debido a la necesidad implícita que requiere de la colaboración entre las partes interesadas en el desarrollo de la actividad turística. En un mercado cada vez más globalizado y competitivo, la creatividad supone un nuevo reto para los destinos turísticos, que buscan posicionarse en los mercados y, a su vez, satisfacer las necesidades de un turista cada vez más interesado en sumergirse en la cultura local. Sin una gestión integral de los recursos con los que cuenta el territorio, sería muy difícil lograr un espacio creativo en el que confluyan turistas y población residente. Para dicha gestión, son necesarios análisis en profundidad que, en consonancia con las características estructurales y socioculturales del espacio analizado, permitan identificar y cuantificar sus recursos.

La creatividad, que ha sido objeto de estudio desde muy diversas perspectivas, adquiere un rol esencial en la puesta en valor de los destinos turísticos, como se evidencia en el desarrollo de este trabajo. Son diversas las metodologías que, a través de índices sintéticos, están enfocadas a analizar y evaluar cuán creativos pueden ser los lugares analizados. En casi todos los casos, la presencia de la comunidad local y de los propios visitantes es crucial para dicha evaluación, además de suponer una herramienta de análisis del territorio que permite inventariar, categorizar y hacer comparables los resultados obtenidos.

Con un fin similar, en este caso centrado en ciudades españolas caracterizadas por tratarse de destinos urbano-culturales, este trabajo tiene como objetivo medir la creatividad de estos territorios y establecer un ranking que permita su comparación. Por tanto, la hipótesis de este trabajo dicta que es factible generar herramientas metodológicas eficaces para medir la creatividad de los destinos turísticos, obteniendo información útil que posibilite el diseño de estrategias enfocadas a mejorar su competitividad.

Para alcanzar este objetivo, se ha creado un índice sintético compuesto de tres grandes dimensiones (espacial, ambiental e institucional) que constituyen subíndices. En aras de dar rigor científico a la metodología propuesta, los componentes de los subíndices han sido evaluados por un panel de expertos que han aportado su experiencia en la creación de una herramienta que permite evaluar la creatividad. 


\section{Marco teórico}

La creatividad juega un papel importante en el desarrollo turístico de muchos territorios, poniendo en valor una amalgama de recursos tangibles e intangibles, cuya combinación resulta efectiva siempre y cuando el turista adquiera un rol activo en las actividades que consume en el destino turístico (Richards \& Marques, 2012). No obstante, hay que matizar que el de creatividad no es un término acuñado recientemente y, desde hace más de sesenta años, ha sido objeto de estudio por diversos autores que identificaron cuatro componentes que dan forma a ésta: el proceso creativo, el producto creativo, la persona creativa y la situación creativa (Mackinnon, 1970; Mooney, 1963). De hecho, estos elementos corresponden al modelo de las cuatro P de la creatividad propuesto por Rhodes (1961): persona, producto, proceso y presión ambiental.

A su vez, la creatividad ha sido estudiada desde perspectivas muy dispares, aportando cada una de ellas sus propias conjeturas y aplicando metodologías afines (Brown, 1989). La neurociencia trata de dar repuesta a los procesos fisiológicos de la creatividad en las personas, estudiando tanto su comportamiento, como los diversos factores que pueden influir en el proceso creativo y los estímulos cerebrales que lo desencadenan (Zabelina, 2018; Zabelina, Hechtman, Saporta, Grunewald \& Beeman, 2020). Por otro lado, cabe destacar el importante papel de la psicología, desde la cual se ha trabajado para comprender la creatividad partiendo de diversos estados mentales y su impacto en el desarrollo de ésta (Orwig, Diez, Vannini Beaty \& Sepulcre, 2021). Finalmente, hay que destacar que la creatividad ha sido abordada incluso por la física cuántica, que invita a profundizar en la atomización sistémica para hallar sentido y el origen al pensamiento divergente (Goswami, 2014).

La perspectiva desde la actividad turística surge hace dos décadas, cuando Richards y Raymond (2000) definieron el turismo creativo como aquel que ofrece a los visitantes la oportunidad de desarrollar su potencial creativo a través de la participación activa en experiencias que son parte de las tradiciones del destino donde se llevan a cabo. Desde ese momento, se hace latente que, para el diseño de la creatividad, son necesarios todos los elementos que caracterizan al sistema turístico, el cual ha sido objeto de análisis por diversos autores, incluida la propia Organización Mundial del Turismo, que propone como tales a la demanda, la oferta, el espacio geográfico y los operadores de mercado (Sancho, 1998). Entre las aportaciones que existen a la configuración del sistema turístico, siempre se ha puesto de manifiesto la importancia del lugar en el que se desarrolla el turismo (Gunn, 1997), al tratarse del destino al que se dirigen los turistas que buscan satisfacer unas necesidades determinadas (Leiper, 1979) y constituye el punto 
en el que se produce la interacción entre el visitante y el entorno local, sobre la cual está basada la creatividad (Richards, 2019).

La creatividad pasa a convertirse en un elemento que contribuye a la competitividad de los territorios, además de suponer un impulso económico para estos. De esta manera, surge la necesidad de medir el impacto de la creatividad para un destino turístico y, por ende, conocer cómo los actores del territorio contribuyen a tal fin. Para satisfacer esta necesidad, surgen varias respuestas basadas en metodologías que desarrollan índices sintéticos para analizar la creatividad en distintas ubicaciones en el mundo. Para ello, Florida y Tinagli (2004) desarrollan el Índice Creativo de las tres T. En el primer caso, se analiza el talento de diversos países, a través de la evaluación de la clase creativa, el capital humano y el talento científico. En segundo lugar, la tecnología se mide a través de la innovación, innovación tecnológica y la inversión en I+D. Finalmente, el indicador de la tolerancia se obtiene a partir la actitud hacia minorías del país en cuestión, sus valores y los derechos individuales y la libertar de expresión existente. Este modelo ha sido ampliamente aceptado y, dado su carácter universal, ha sido objeto de revisiones y aplicaciones en diferentes territorios con el objetivo de conocer su capital creativo. Además, es destacable la vigencia de este análisis de la creatividad basado en las tres $T$, siendo adaptado y utilizado en un destino turístico internacional como la Costa del Sol (Romero-Padilla, Navarro-Jurado \& Romero-Martínez, 2020).

Como se puede apreciar, la creatividad no sólo depende de un espacio cuyas características culturales lo hagan único, sino que demanda recursos humanos que generen dinamismo en estos, ya sea en el caso de actores privados que hagan uso de la creatividad para fomentar la cultura, o actores públicos que intervengan e inviertan en el mantenimiento y puesta en valor de los recursos culturales (Lucia \& Trunfio, 2018). Del mismo modo, adquiere una gran importancia la cooperación entre la población residente y los turistas, resultando en un impacto muy positivo para el desarrollo del territorio y beneficiando de esa manera a la propia población local, que juega un papel fundamental a la hora de desempeñar las actividades tradicionales que los visitantes más creativos buscan conocer (Richards, Wisansing \& Paschinger, 2019).

De hecho, esta interacción entre los actores locales y los turistas ya ha sido objeto de estudio por trabajos enfocados a analizar la experiencia turística desde una perspectiva sistémica, es decir, teniendo en cuenta al turista como una de las partes esenciales en el proceso de generación de experiencias, la co-creación (Jager, 2009). La generación de experiencias basadas en la cocreación pone en relieve la participación del turista en el proceso productivo y acentúa la 
importancia de la interacción con la población local (Binkhorst, 2007; Lugosi \& Walls, 2013; Richards, 2010). Por tanto, la creatividad contribuye de forma directa al beneficio de la población local, lo que sustenta uno de los pilares básicos para el desarrollo sostenible del turismo y que es necesario tener en cuenta a la hora de gestionar la cadena de valor del destino turístico. Asimismo, la creatividad supone la mejora económica de los destinos urbano-culturales, dándose un mayor gasto por parte de los turistas interesados en este tipo de destinos (PulidoFernández, Cárdenas-García \& Carrillo-Hidalgo, 2016). No obstante, aunque la sostenibilidad implica tener en consideración a todos los actores implicados en el destino, las necesidades de la comunidad local son de vital importancia en todo el proceso de gestión turística (PulidoFernández \& López-Sánchez, 2016).

Por otro lado, siguiendo la línea del Índice Creativo de las tres T, surgieron otros trabajos enfocados a evaluar la competitividad de las ciudades a partir de la medición de la creatividad. El Índice Creativo de Hong Kong propuesto por Hui, Mok, Ngai, Wan-Kan y Yuen (2005) hace uso de 84 indicadores que analizan aspectos sociales, culturales, estructurales y humanos. Por su parte, Landry (2010) mide la creatividad en la ciudad de Bilbao a partir de las opiniones de los diversos sectores, como la educación, el sector privado y el cultural, teniendo en cuenta la perspectiva de la población local y el público en general. Ambos índices tienen como punto de partida analizar a todos las partes interesadas que concurren en un determinado territorio, en este caso, ciudades y regiones delimitadas por fronteras administrativas.

La medición de la creatividad, como se acaba de ver, recae, en gran parte, en lo que dentro del sistema turístico corresponde con la región receptora de turistas desde el punto de vista del sistema turístico de Leiper (1990). Éste se caracteriza como el lugar contemplado por el turista para su visita dadas sus características. Dicha región estará configurada, según lo expuesto por Cooper y Hall (2008), por las atracciones y culturales, las instalaciones y servicios junto a los recursos humanos, la accesibilidad al destino en forma de infraestructuras y, finalmente, la información que se provee al visitante. En consecuencia, y atendiendo a la característica común de los territorios como receptores de turistas, se puede hablar de un sistema turístico local si cuenta con los elementos suficientes para generar la atracción de visitantes. Esta visión sistémica del turismo es necesaria cuando se trata la creatividad de los destinos, ya que se toma en consideración la participación del turista en el destino (de Bruin \& Jelinčić, 2016), lo que implica aprovechar los recursos endógenos para crear experiencias de las que los turistas formarán parte (Jelinčić \& Zuvela, 2012). 
En la actualidad, la creatividad juega un papel fundamental, no sólo para el turismo en sí, sino para la planificación y la configuración de las ciudades. Modelos de planificación, como el placemaking, implican procesos colaborativos a través de los cuales se da forma a las ciudades para maximizar la generación de valor, en los que la comunidad local cobra protagonismo (PPS, 2014). Este proceso, en su conjunto, está cada vez más vinculado a la actividad turística, debido a que su planificación y diseño requiere de una fuerte vinculación a la cultura local, hecho que va a crear experiencias auténticas entre los turistas que visitan un destino (Lew, 2017). En este sentido, un entorno que estimula la atracción de capital humano creativo deberá responder positivamente al modelo de las tres $T$ expuesto anteriormente, en especial a las dimensiones tolerancia y talento (Beier, Clavé \& Vigier, 2020).

De hecho, la vinculación entre turismo y placemaking se acentúa cuando está presente el diseño y planificación de lugares enfocados a desarrollar su actividad, en los que necesariamente la creatividad se ha convertido en la base principal sobre la que recaen todas las estrategias que movilizan al conjunto de actores y recursos de un territorio, respondiendo a una visión holística de éste. Por otra parte, hay que tener muy en cuenta algunas características espaciales, económicas o distributivas de los territorios sobre los que aplicar las metodologías, que exigen estar diseñadas para tal fin o bien ser flexibles para adaptarlas al trabajo de campo (Richards, 2020). Esta aproximación al placemaking resalta la forma de actuar a la hora de planificar y desarrollar herramientas para la medición de la creatividad en el territorio, como, en el caso de este artículo, en destinos urbano-culturales. Como resultado, se obtiene una propuesta de ecosistema turístico creativo en el ámbito de los destinos urbano-culturales.

\section{Metodología}

A partir de una revisión profunda de la literatura existente, y para poder medir la creatividad en los destinos urbano-culturales a través de un índice sintético, se idea una propuesta de ecosistema turístico en el ámbito de estas ciudades, que tiene a la creatividad como punto central. El análisis de estos ecosistemas se realiza a través del diseño de un sistema de indicadores que abastece las tres dimensiones en las que se organizan tales ecosistemas (espacial, ambiental e institucional). Dicha revisión parte de una búsqueda inicial en las principales bases de datos (Web of Science en primer lugar, seguida de Scopus y, finalmente, Google Scholar) mediante el uso de términos clave como "creativity" "creativity assessment in cities" "creativity indicators" y "creativity in tourism", y la aplicación del filtro para resaltar los artículos más citados y, por ende, los más relevantes. Además, fue necesario limitar los trabajos 
a las áreas de ciencias sociales, economía, gestión y econometría para poder obtener los resultados afines a la actividad turística. Una vez analizados estos trabajos, mediante la técnica de bola de nieve, se identifican aquellos que han desarrollado metodologías basadas en indicadores y/o que posean un carácter empírico.

El método Delphi ha sido la herramienta empleada para la validación del sistema de indicadores propuesto. Éste se identifica como una técnica de previsión de la incertidumbre (Godet, 1996) o de acontecimientos futuros (Astigarraga, 2008), pero, sobre todo, de diagnóstico de problemas que necesiten de un juicio u opinión fundada (Glenn, 1999). Además, requiere de la conformación de un panel de expertos, al objeto de consensuar objetivamente la subjetividad que aporta la opinión basada en el conocimiento y experiencia de cada uno de los integrantes. La novedad del tema de esta investigación hace que se tenga que recurrir a una técnica que encuentre en el conocimiento grupal, la retroalimentación y el consenso una guía de navegación certera (Kaymack \& Macaulay, 1984). Además, como advierte Pulido (2007, p. 115), "el Delphi es aplicable cuando es necesario contrastar y combinar argumentos para llegar a decisiones no asumibles unilateralmente", siendo éste un caso de ellos. Respecto a su dinámica metodológica, lo habitual es que sean dos etapas de envíos de cuestionarios, siempre y cuando se alcance un suficiente grado de consenso, lo que se evidencia con la reducción del espacio intercuartil en las respuestas de los integrantes del panel de expertos seleccionado.

El panel de expertos con los que se trabaja en esta investigación, se compone de ocho personas. Es importante recordar que, aunque los paneles de expertos se componen, normalmente, de entre 10 y 100 participantes (Avella, 2016), se han llevado a cabo estudios con paneles de tamaños muy diversos (Akins, Tolson \& Cole, 2005). De hecho, Gable y Wolf (1993) y Grant y Davis (1997) sugieren un tamaño óptimo de entre dos y veinte participantes para los paneles de expertos. Para el caso que nos ocupa, cabe recordar que no es fácil encontrar expertos en la materia objeto de estudio y que, aunque el panel diseñado es reducido en cuanto al número de participantes, sin embargo, el conocimiento técnico de los mismos era muy alto, lo que permitió suplir la escasez de expertos.

La consulta con el panel de expertos ha permitido definir el sistema de indicadores con treinta y cuatro variables finales, a pesar de comenzar la propuesta a los expertos analizando sesenta y cuatro. Tras la segunda ronda, se considera que se alcanza el suficiente consenso (valoración 5 7 y desviación típica 1) en un número importante de indicadores, por lo que se decide no realizar una nueva circulación y se procede a la selección definitiva de los indicadores. Para 
alcanzar este punto, cada indicador fue evaluado por el panel de expertos a través de una escala Likert de 1 a 7 (totalmente en desacuerdo, bastante en desacuerdo, parcialmente en desacuerdo, neutral, parcialmente de acuerdo, bastante de acuerdo y totalmente de acuerdo). Para el tratamiento estadístico de los cuestionarios, se utilizó el software estadístico SPSS. Como medida de tendencia central se optó por la mediana (Q2) y como medida de dispersión, el recorrido intercuartílico (Q3-Q1) que muestra una mayor estabilidad en las respuestas cuanto menor sea su valor.

Una vez desarrollado y finalizado el sistema de indicadores, se decide aplicar sobre 20 ciudades turísticas urbano culturales más importantes de España, las cuales fueron identificadas por Exceltur en 2012 en su estudio UrbanTUR sobre competitividad. Las ciudades elegidas han sido: Alicante, Barcelona, Bilbao, Burgos, Córdoba, Granada, Gijón, La Coruña, León, Madrid, Málaga, Oviedo, Salamanca, San Sebastián, Santander, Santiago de Compostela, Sevilla, Toledo, Valencia y Zaragoza. Cabe mencionar, que algunos de los indicadores que dan forma a la metodología desarrollada se han diseñado tomando como referencia fuentes estadísticas y ciudades españolas, por lo que su replicabilidad a nivel internacional puede requerir de una restructuración y revisión de las diversas variables analizadas en cada dimensión.

\subsection{El Î́ndice Sintético Creacity}

Para conocer el peso específico, se crea un índice sintético que permite conocer la predisposición creativa del destino. Este índice, que se denomina Creacity, y sus variables persiguen detectar:

1. en la creatividad espacial, el conocimiento del número e importancia de los espacios físicos que facilitan el desarrollo de la creatividad, así como su difusión y comunicación mediante 11 indicadores.

2. en la creatividad ambiental, el conocimiento de talento personal de la población, el peso de las clases creativas en el conjunto de la población junto a su actividad, las propuestas para alimentar nuestra creatividad y los comportamientos que tienden a configurar el ambiente creativo que respira un destino turístico a través de 15 indicadores y, por último,

3. en la creatividad institucional, el conocimiento sobre el grado de creatividad y de estimulación de la misma que presenta el marco institucional de un destino turístico, en este caso de tipología urbano cultural, medido por 8 indicadores. 
El índice se compone de indicadores (Tablas 1, 2 y 3) que inciden sobre elementos clave del ser creativo, el entorno creativo, el proceso creativo y el producto creativo. Un especial peso en el diseño de Creacity tienen los índices que, desde dos instituciones académicas e investigadoras, abordan el estudio de la creatividad en los sistemas económicos a nivel estatal. Por un lado, Innometrics y su Design, Creativity and Innovation: A Scoreboard Approach, proyecto dirigido por Hollanders y van Cruysen (2009). De otro, el conocido como Índice de Creatividad de Hong Kong (Hui et al., 2005). También se tiene en cuenta la metodología de Landry (2010) sobre creatividad y ciudades, aunque se debe mencionar que este investigador se basa en encuestas de opinión sobre percepción creativa (Know cities in the Atlantic Arc, 2012 y el Índice de Creatividad en Billbao/Vizcaya, 2010), por lo que, en este trabajo, se prefiere utilizar datos objetivos (tanto de fuentes secundarias como primarias), en línea con Innometrics o bien Florida (2009), Florida y Tinagli (2004) o Florida et al. (2015). Aunque existen otras propuestas de índices para medir la creatividad en sistemas territoriales (Clifton et al., 2013; González et al., 2016; Pesquera et al. 2010), éstas no dejan de estar basadas exclusivamente en la teoría de Florida de las tres T. Este trabajo propone la aplicación novedosa de una metodología (DP2) aplicada en otros campos que supone un antes y un después en la medición de la creatividad en los territorios, creando e implementando un sistema de indicadores diseñado exclusivamente para ciudades con sendas características culturales. Además, toma como base trabajos de ámbito internacional que han sido ampliamente aceptados, los cuales contribuyen a la mejora del conocimiento de los territorios y a descubrir su potencial competitivo a partir de un conjunto de elementos transversales que apoyan a la creatividad. 
Tabla 1. Indicadores CREACITY Espacial

\begin{tabular}{|c|c|c|c|c|c|c|}
\hline DIMENSIÓN & AREA & ID & INDICADOR & $\begin{array}{l}\text { ANTECEDENTES / } \\
\text { REFERENCIAS }\end{array}$ & $\begin{array}{c}\text { DESCRIPCIÓN } \\
\text { PROXY } \\
\text { SELECCIONADO }\end{array}$ & FUENTE \\
\hline \multirow{6}{*}{ ESPACIAL } & \multirow[t]{3}{*}{$\begin{array}{l}\text { Espacios } \\
\text { culturales y } \\
\text { creativos }\end{array}$} & CE1 & $\begin{array}{l}\text { Espacios } \\
\text { culturales y } \\
\text { creativos. }\end{array}$ & $\begin{array}{l}\text { Hui el al. (2005) } \\
\text { Landry (2008) }\end{array}$ & $\begin{array}{l}\text { Total teatros; } \\
\text { museos; centros } \\
\text { de interpretación; } \\
\text { salas de } \\
\text { conferencias; } \\
\text { centros de } \\
\text { congresos; } \\
\text { centros cívicos; } \\
\text { centros culturales } \\
\text { y bibliotecas por } \\
\text { cada } 100.000 \\
\text { habitantes. }\end{array}$ & Ayuntamientos \\
\hline & & CE2 & $\begin{array}{l}\text { Edificios } \\
\text { declarados Bien } \\
\text { de Interés } \\
\text { Cultural; } \\
\text { conjuntos } \\
\text { históricos y } \\
\text { conjuntos } \\
\text { monumentales. }\end{array}$ & $\begin{array}{l}\text { Hui el al. (2005) } \\
\text { Landry (2008) }\end{array}$ & $\begin{array}{l}\text { Edificios y } \\
\text { conjuntos } \\
\text { declarados en el } \\
\text { municipio. }\end{array}$ & $\begin{array}{l}\text { Ministerio de } \\
\text { Educación y } \\
\text { Cultura }\end{array}$ \\
\hline & & CE3 & $\begin{array}{l}\text { Patrimonio } \\
\text { cultural con } \\
\text { declaración de } \\
\text { Patrimonio de } \\
\text { la } \\
\text { Humanidad. }\end{array}$ & $\begin{array}{l}\text { Hui et al. (2005) } \\
\text { Landry (2008) }\end{array}$ & $\begin{array}{l}\text { Declaraciones } \\
\text { Patrimonio de la } \\
\text { Humanidad en el } \\
\text { municipio. }\end{array}$ & UNESCO \\
\hline & \multirow[t]{3}{*}{$\begin{array}{l}\text { Centros } \\
\text { académicos que } \\
\text { fomenten la } \\
\text { creatividad }\end{array}$} & CE4 & $\begin{array}{l}\text { Escuelas de } \\
\text { Música; } \\
\text { escuelas } \\
\text { de Idiomas, } \\
\text { escuelas de } \\
\text { Danza y } \\
\text { escuelas } \\
\text { de Teatro. } \\
\end{array}$ & $\begin{array}{l}\text { Hollanders y van } \\
\text { Cruysen (2009) } \\
\text { Hui et al. (2005) } \\
\text { Huidrobo (2002) } \\
\text { Landry (2008) }\end{array}$ & $\begin{array}{l}\text { Centros por cada } \\
100.000 \\
\text { habitantes. }\end{array}$ & Ayuntamientos \\
\hline & & CE5 & 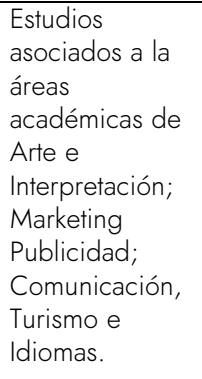 & $\begin{array}{l}\text { Huidrobo (2002), } \\
\text { Hui et al. (2005), } \\
\text { Hollanders y van } \\
\text { Cruysen (2009), } \\
\text { Landry (2010) }\end{array}$ & $\begin{array}{l}\text { Estudios por cada } \\
100.000 \\
\text { habitantes. }\end{array}$ & $\begin{array}{c}\text { Universidades } \\
\text { públicas y } \\
\text { privadas }\end{array}$ \\
\hline & & CE6 & $\begin{array}{l}\text { Centros } \\
\text { tecnológicos y } \\
\text { de innovación. }\end{array}$ & $\begin{array}{c}\text { Florida and Tinagli } \\
\text { (2004), } \\
\text { Hui et al. (2005), } \\
\text { Hollanders and van } \\
\text { Cruysen (2009), } \\
\text { Landry (2010) }\end{array}$ & $\begin{array}{l}\text { Centros por cada } \\
100.000 \\
\text { habitantes. }\end{array}$ & $\begin{array}{c}\text { Ministerio de } \\
\text { Economía y } \\
\text { Competitividad }\end{array}$ \\
\hline
\end{tabular}


Tabla 1. Continuación

\begin{tabular}{|c|c|c|c|c|c|c|}
\hline DIMENSIÓN & AREA & ID & INDICADOR & $\begin{array}{c}\text { ANTECEDENTES / } \\
\text { REFERENCIAS }\end{array}$ & $\begin{array}{c}\text { DESCRIPCIÓN } \\
\text { PROXY } \\
\text { SELECCIONADO }\end{array}$ & FUENTE \\
\hline & \multirow[t]{3}{*}{$\begin{array}{l}\text { Establecimientos } \\
\text { turísticos } \\
\text { de singularidad } \\
\text { creativa }\end{array}$} & CE7 & $\begin{array}{l}\text { Restaurantes } \\
\text { ubicados en } \\
\text { edificios de } \\
\text { singularidad } \\
\text { arquitectónica. }\end{array}$ & $\begin{array}{c}\text { Richards y Wilson } \\
(2006)\end{array}$ & $\begin{array}{l}\text { Total restaurantes } \\
\text { ubicados en } \\
\text { edificios } \\
\text { declarados Bien } \\
\text { de Interés Cultural. }\end{array}$ & $\begin{array}{c}\text { Ministerio } \\
\text { Educación, Cultura } \\
\text { y } \\
\text { Deporte y las webs } \\
\text { turísticas } \\
\text { oficiales de las } 20 \\
\text { ciudades } \\
\text { analizadas en el } \\
\text { estudio }\end{array}$ \\
\hline & & CE8 & $\begin{array}{l}\text { Restaurantes } \\
\text { con estrellas } \\
\text { Michelín. }\end{array}$ & $\begin{array}{c}\text { Richards y Wilson } \\
\text { (2006) }\end{array}$ & $\begin{array}{l}\text { Los restaurantes } \\
\text { son valorados } \\
\text { dependiendo de } \\
\text { las estrellas que } \\
\text { posean (tres } \\
\text { estrellas } \\
\text { valor triple, dos } \\
\text { estrellas valor } \\
\text { doble y una estrella } \\
\text { valor simple). }\end{array}$ & Guía Michelin \\
\hline & & CE9 & $\begin{array}{l}\text { Alojamientos } \\
\text { ubicados en } \\
\text { edificios de } \\
\text { gran } \\
\text { singularidad } \\
\text { arquitectónica. }\end{array}$ & $\begin{array}{c}\text { Richards y Wilson } \\
\text { (2006) }\end{array}$ & $\begin{array}{l}\text { Total hoteles } \\
\text { ubicados en } \\
\text { edificios } \\
\text { declarados Bien } \\
\text { de Interés Cultural. }\end{array}$ & $\begin{array}{c}\text { Ministerio } \\
\text { Educación, Cultura } \\
\text { y } \\
\text { Deporte y } \\
\text { elaboración propia }\end{array}$ \\
\hline & \multirow[t]{2}{*}{$\begin{array}{l}\text { Conectividad } \\
\text { física y } \\
\text { digital }\end{array}$} & CE10 & $\begin{array}{l}\text { Accesibilidad y } \\
\text { movilidad } \\
\text { urbana } \\
\text { en relación al } \\
\text { turismo. }\end{array}$ & $\begin{array}{c}\text { Landry (2010), } \\
\text { Richards y Wilson } \\
\text { (2006) }\end{array}$ & $\begin{array}{l}\text { Pilar cuatro del } \\
\text { índice } \\
\text { sintético UrbanTUR }{ }^{1} \text {. } \\
\text { Accesibilidad y } \\
\text { movilidad que } \\
\text { toma como } \\
\text { referencia doce } \\
\text { indicadores para } \\
\text { este tema. }\end{array}$ & UrbanTUR \\
\hline & & CE11 & $\begin{array}{l}\text { Accesibilidad } \\
\text { digital. } \\
\text { Adecuación de } \\
\text { la web que } \\
\text { representa al } \\
\text { destino a las } \\
\text { necesidades } \\
\text { del } \\
\text { mercado. }\end{array}$ & $\begin{array}{l}\text { Hui et al. (2005), } \\
\text { Landry (2010), } \\
\text { Richards y Wilson } \\
\text { (2006) }\end{array}$ & $\begin{array}{l}\text { Dentro del pilar } \\
\text { cinco } \\
\text { del índice Urbatur, } \\
\text { apartado Política } \\
\text { de marketing y } \\
\text { promoción } \\
\text { turística a través } \\
\text { de nuevos canales } \\
\text { on-line que toma } \\
\text { como referencia } \\
\text { indicadores. }\end{array}$ & UrbanTUR \\
\hline
\end{tabular}

Fuente: elaboración propia

1 UrbanTUR es el primer monitor de competitividad turística que analiza la posición relativa de las 20 ciudades españolas más exitosas en función de su mayor volumen de viajeros recibidos en los últimos cinco años. 
Tabla 2. Indicadores CREACITY Ambiental

\begin{tabular}{|c|c|c|c|c|c|c|}
\hline DIMENSIÓN & AREA & ID & INDICADOR & $\begin{array}{l}\text { ANTECEDENTES / } \\
\text { REFERENCIAS }\end{array}$ & $\begin{array}{l}\text { DESCRIPCIÓN PROXY } \\
\text { SELECCIONADO }\end{array}$ & FUENTE \\
\hline \multirow{8}{*}{ AMBIENTAL } & $\begin{array}{l}\text { Clases } \\
\text { creativas y } \\
\text { producción } \\
\text { creativa }\end{array}$ & CA1 & $\begin{array}{l}\text { Actividades } \\
\text { económicas } \\
\text { creativas. }\end{array}$ & $\begin{array}{c}\text { Florida (2002), } \\
\text { Florida et al. } \\
\text { (2015), Florida y } \\
\text { Tinagli } \\
\text { (2004), } \\
\text { Hollanders y van } \\
\text { Cruysen (2009), } \\
\text { Hui et al. (2005), } \\
\text { Landry (2008), } \\
\text { Richards y Wilson } \\
\text { (2006) }\end{array}$ & $\begin{array}{l}\text { Número de } \\
\text { actividades } \\
\text { económicas } \\
\text { creativas por cada } \\
100.000 \\
\text { habitantes. }\end{array}$ & Censo INE $^{2}$ \\
\hline & \multirow[t]{5}{*}{$\begin{array}{l}\text { Clases creativas y } \\
\text { producción } \\
\text { creativa }\end{array}$} & CA2 & $\begin{array}{l}\text { Peso de las } \\
\text { industrias creativas } \\
\text { en la actividad } \\
\text { económica. }\end{array}$ & $\begin{array}{c}\text { Florida (2002), } \\
\text { Florida et al. } \\
\text { (2015), Florida y } \\
\text { Tinagli (2004), } \\
\text { Hollanders and van } \\
\text { Cruysen (2009), } \\
\text { Hui et al. } \\
\text { (2005), Landry } \\
\text { (2008), Richards y } \\
\text { Wilson (2006) }\end{array}$ & $\begin{array}{l}\text { Porcentaje que } \\
\text { presentan las } \\
\text { industrias } \\
\text { creativas en el } \\
\text { total de la } \\
\text { actividad } \\
\text { económica. }\end{array}$ & Censo INE \\
\hline & & CA3 & $\begin{array}{l}\text { Innovación en } \\
\text { marcas. }\end{array}$ & $\begin{array}{l}\text { Hollanders and van } \\
\text { Cruysen (2009) }\end{array}$ & $\begin{array}{l}\text { Número de } \\
\text { solicitudes de } \\
\text { marcas por cada } \\
100.000 \\
\text { habitantes. }\end{array}$ & $\begin{array}{c}\text { OEPM } \\
\text { (Oficina } \\
\text { Española de } \\
\text { Patentes y } \\
\text { Marcas) }\end{array}$ \\
\hline & & CA4 & $\begin{array}{l}\text { Innovación en } \\
\text { patentes. }\end{array}$ & $\begin{array}{c}\text { Florida (2002), } \\
\text { Florida et al. } \\
\text { (2015), Florida y } \\
\text { Tinagli } \\
\text { (2004), } \\
\text { Hollanders y van } \\
\text { Cruysen (2009), } \\
\text { Hui et al. (2005) }\end{array}$ & $\begin{array}{l}\text { Número de } \\
\text { solicitudes de } \\
\text { patentes por cada } \\
100.000 \\
\text { habitantes. }\end{array}$ & OEPM \\
\hline & & CA5 & $\begin{array}{l}\text { Producción } \\
\text { científica en } \\
\text { turismo. }\end{array}$ & $\begin{array}{l}\text { Hollanders y van } \\
\text { Cruysen (2009) }\end{array}$ & $\begin{array}{l}\text { Publicaciones } \\
\text { científicas } \\
\text { relacionadas con } \\
\text { el área del turismo } \\
\text { por cada } 100.000 \\
\text { habitantes. Si hay } \\
\text { varios autores, la } \\
\text { puntuación se } \\
\text { divide } \\
\text { proporcionalmente } \\
\text { entre los } \\
\text { existentes. }\end{array}$ & $\begin{array}{c}\text { Moreno y } \\
\text { Picazo (2012) }\end{array}$ \\
\hline & & CA6 & $\begin{array}{l}\text { Calidad del } \\
\text { sistema } \\
\text { educativo } \\
\text { universitario. }\end{array}$ & $\begin{array}{l}\text { Hollanders y van } \\
\text { Cruysen (2009) }\end{array}$ & $\begin{array}{l}\text { Posición en el } \\
\text { ranking de calidad } \\
\text { del sistema } \\
\text { educativo } \\
\text { universitario. }\end{array}$ & $\begin{array}{l}\text { U-ranking } \\
\text { ISSUE-P / } \\
\text { Fundación } \\
\text { BBVA }\end{array}$ \\
\hline & \multirow[t]{2}{*}{$\begin{array}{l}\text { Oferta y flujo } \\
\text { turístico cultural }\end{array}$} & CA7 & $\begin{array}{l}\text { Flujo turístico a } \\
\text { monumentos. }\end{array}$ & Hui et al. (2005) & $\begin{array}{l}\text { Visitantes totales a } \\
\text { Monumentos, } \\
\text { proporcionadas por la } \\
\text { población. }\end{array}$ & $\begin{array}{l}\text { Observatorios } \\
\text { turísticos } \\
\text { municipales, } \\
\text { provinciales y } \\
\text { regionales }\end{array}$ \\
\hline & & CA8 & $\begin{array}{l}\text { Flujo turístico a } \\
\text { museos. }\end{array}$ & Hui et al. (2005) & $\begin{array}{l}\text { Visitantes totales a } \\
\text { museos } \\
\text { proporcionados por la } \\
\text { población. }\end{array}$ & $\begin{array}{l}\text { Observatorios } \\
\text { turísticos } \\
\text { municipales, } \\
\text { provinciales y } \\
\text { regionales }\end{array}$ \\
\hline
\end{tabular}

2 Instituto Nacional de Estadística de España. 
Tabla 2. Continuación

\begin{tabular}{|c|c|c|c|c|c|c|}
\hline DIMENSIÓN & AREA & ID & INDICADOR & $\begin{array}{l}\text { ANTECEDENTES / } \\
\text { REFERENCIAS }\end{array}$ & $\begin{array}{ll}\text { DESCRIPCIÓN } & \text { PROXY } \\
\text { SELECCIONADO } & \end{array}$ & FUENTE \\
\hline \multirow[t]{8}{*}{ AMBIENTAL } & \multirow[t]{3}{*}{$\begin{array}{l}\text { Oferta y flujo } \\
\text { turístico cultural }\end{array}$} & CA9 & $\begin{array}{l}\text { Calidad e } \\
\text { innovación de la } \\
\text { oferta cultural. }\end{array}$ & Hui et al. (2005) & $\begin{array}{l}\text { Valoración del } \\
\text { nivel de calidad e } \\
\text { innovación de la } \\
\text { oferta cultural. } \\
\text { según el } \\
\text { Observatorio de } \\
\text { la Cultura. }\end{array}$ & $\begin{array}{l}\text { Observatorio de } \\
\text { la Cultura. } \\
\text { Fundación } \\
\text { Contemporánea }\end{array}$ \\
\hline & & CA10 & $\begin{array}{l}\text { Actividad de } \\
\text { congresos y } \\
\text { reuniones. }\end{array}$ & Landry (2008) & $\begin{array}{l}\text { Apartado } \\
\text { Resultado de la } \\
\text { actividad de ferias, } \\
\text { reuniones y } \\
\text { congresos del } \\
\text { índice sintético } \\
\text { UrbanTUR, que } \\
\text { contempla dos } \\
\text { indicadores. }\end{array}$ & UrbanTUR \\
\hline & & CA11 & $\begin{array}{l}\text { Turismo } \\
\text { idiomático. }\end{array}$ & $\begin{array}{c}\text { Richards y Raymond } \\
(2000), \\
\text { Unesco (2006) }\end{array}$ & $\begin{array}{l}\text { Número total de } \\
\text { centros asociados } \\
\text { del Instituto } \\
\text { Cervantes proporcionados } \\
\text { por la población. }\end{array}$ & $\begin{array}{l}\text { Instituto } \\
\text { Cervantes }\end{array}$ \\
\hline & \multirow[t]{5}{*}{$\begin{array}{l}\text { Apertura, } \\
\text { tolerancia, } \\
\text { calidad de } \\
\text { viday } \\
\text { participación } \\
\text { ciudadana }\end{array}$} & CA12 & Homosexualidad. & $\begin{array}{c}\text { Florida (2002), } \\
\text { Florida et al. (2015), } \\
\text { Florida y Tinagli } \\
\text { (2004), } \\
\text { Hollanders y van } \\
\text { Cruysen (2009), } \\
\text { Hui et al. (2005), } \\
\text { Landry (2008), } \\
\text { Richards y Wilson } \\
\text { (2006) }\end{array}$ & $\begin{array}{l}\text { Matrimonios del } \\
\text { mismo sexo por } \\
\text { cada } 1.000 \\
\text { matrimonios. }\end{array}$ & Censo INE \\
\hline & & CA13 & Multiculturalidad. & $\begin{array}{c}\text { Florida (2002), } \\
\text { Florida et al. (2015), } \\
\text { Florida y Tinagli } \\
\text { (2004), } \\
\text { Hollanders y van } \\
\text { Cruysen (2009), } \\
\text { Hui et al. (2005), } \\
\text { Landry (2008), } \\
\text { Richards y Wilson } \\
\text { (2006) }\end{array}$ & $\begin{array}{l}\text { Porcentaje de } \\
\text { población } \\
\text { extranjera } \\
\text { residente con } \\
\text { respecto al total. }\end{array}$ & Censo INE \\
\hline & & CA14 & $\begin{array}{l}\text { Participación } \\
\text { ciudadana. }\end{array}$ & Landry (2010) & $\begin{array}{l}\text { Participación } \\
\text { electoral en las } \\
\text { elecciones } \\
\text { municipales. }\end{array}$ & $\begin{array}{l}\text { Ministerio del } \\
\text { Interior }\end{array}$ \\
\hline & & CA15 & Calidad de vida. & $\begin{array}{l}\text { Florida (2009), } \\
\text { Landry (2010) }\end{array}$ & $\begin{array}{l}\text { Apartado } \\
\text { indicador } \\
\text { Condicionantes } \\
\text { competitivos del } \\
\text { entorno urbano y } \\
\text { de la vida local en } \\
\text { el municipio que } \\
\text { toma como } \\
\text { referencia nueve } \\
\text { indicadores. }\end{array}$ & UrbanTUR \\
\hline & & CA15 & Calidad de vida. & $\begin{array}{l}\text { Florida (2009), } \\
\text { Landry (2010) }\end{array}$ & $\begin{array}{l}\text { Apartado } \\
\text { indicador } \\
\text { Condicionantes } \\
\text { competitivos del } \\
\text { entorno urbano y } \\
\text { de la vida local en } \\
\text { el municipio que } \\
\text { toma como } \\
\text { referencia nueve } \\
\text { indicadores. }\end{array}$ & UrbanTUR \\
\hline
\end{tabular}

Fuente: elaboración propia 
Tabla 3. Indicadores CREACITY Institucional

\begin{tabular}{|c|c|c|c|c|c|c|}
\hline DIMENSIÓN & AREA & ID & INDICADOR & $\begin{array}{l}\text { ANTECEDENTES/ } \\
\text { REFERENCIAS }\end{array}$ & $\begin{array}{l}\text { DESCRIPCIÓN PROXY } \\
\text { SELECCIONADO }\end{array}$ & FUENTE \\
\hline \multirow{8}{*}{ INSTITUCIONAL } & \multirow[t]{2}{*}{$\begin{array}{l}\text { Gobierno } \\
\text { abierto }\end{array}$} & $\mathrm{Cl} 1$ & $\begin{array}{l}\text { Transparencia } \\
\text { administrativa. }\end{array}$ & Hui et al. (2005) & $\begin{array}{l}\text { Grado de } \\
\text { implantación de la } \\
\text { Administración } \\
\text { municipal. Índice } \\
\text { de Transparencia } \\
\text { en la } \\
\text { Administración } \\
\text { (TI). }\end{array}$ & $\begin{array}{c}\text { Transparencia } \\
\text { Internacional } \\
\text { España }\end{array}$ \\
\hline & & $\mathrm{Cl} 2$ & $\begin{array}{l}\text { Administración } \\
\text { electrónica. }\end{array}$ & $\begin{array}{l}\text { Hui et al. (2005), } \\
\text { Landry (2010), } \\
\text { Richards and Wilson } \\
\text { (2007) }\end{array}$ & $\begin{array}{l}\text { Grado de } \\
\text { implantación de la } \\
\text { Administración } \\
\text { electrónica. índice } \\
\text { Fundación } \\
\text { Orange. }\end{array}$ & $\begin{array}{c}\text { Fundación } \\
\text { Orange }\end{array}$ \\
\hline & \multirow[t]{2}{*}{$\begin{array}{l}\text { Gestión } \\
\text { estratégica } \\
\text { del turismo }\end{array}$} & $\mathrm{Cl} 3$ & $\begin{array}{l}\text { Existencia y } \\
\text { consistencia de } \\
\text { una visión } \\
\text { estratégica del } \\
\text { turismo. }\end{array}$ & Landry (2010) & $\begin{array}{l}\text { Apartado } \\
\text { indicador } \\
\text { Existencia de una } \\
\text { visión estratégica } \\
\text { del turismo del } \\
\text { índice sintético } \\
\text { UrbanTUR. }\end{array}$ & UrbanTUR \\
\hline & & $\mathrm{Cl} 4$ & Clustering. & $\begin{array}{l}\text { Richards and Wilson } \\
\text { (2007) }\end{array}$ & $\begin{array}{l}\text { Apartado } \\
\text { indicador } \\
\text { Desarrollo y } \\
\text { gestión integral } \\
\text { de la oferta por } \\
\text { clubes de } \\
\text { productos del } \\
\text { índice sintético } \\
\text { UrbanTUR. }\end{array}$ & UrbanTUR \\
\hline & $\begin{array}{l}\text { Talento } \\
\text { institucional }\end{array}$ & $\mathrm{Cl} 5$ & $\begin{array}{l}\text { Presencia de } \\
\text { talento en los } \\
\text { órganos de } \\
\text { gestión turística. }\end{array}$ & $\begin{array}{c}\text { Landry (2008), } \\
\text { Richards and Wilson } \\
\text { (2007) }\end{array}$ & $\begin{array}{l}\text { Número de doctores } \\
\text { existentes en los entes de } \\
\text { gestión } \\
\text { turística del } \\
\text { sistema turístico } \\
\text { local. }\end{array}$ & LinKedln \\
\hline & $\begin{array}{l}\text { Estimulación } \\
\text { creativa }\end{array}$ & $\mathrm{Cl} 6$ & $\begin{array}{l}\text { Imagen destino } \\
\text { creativo. }\end{array}$ & $\begin{array}{c}\text { Florida (2008), } \\
\text { Richards and Wilson } \\
\text { (2007) }\end{array}$ & $\begin{array}{l}\text { Pertenencia a } \\
\text { redes de ciudades } \\
\text { creativas } \\
\text { (Ciudades } \\
\text { Europeas } \\
\text { Culturales, Red de } \\
\text { Ciudades } \\
\text { Creativas de la } \\
\text { Unesco y la Red } \\
\text { Creative Tourism } \\
\text { Network). }\end{array}$ & $\begin{array}{c}\text { Unesco, Unión } \\
\text { Europea y } \\
\text { Crea }\end{array}$ \\
\hline & \multirow[t]{2}{*}{$\begin{array}{l}\text { Estimulación } \\
\text { creativa }\end{array}$} & $\mathrm{Cl} 7$ & $\begin{array}{l}\text { Emprendimiento } \\
\text { creativo. }\end{array}$ & $\begin{array}{c}\text { Huidrobo (2002), } \\
\text { Richards and Wilson } \\
(2007)\end{array}$ & $\begin{array}{l}\text { Existencia de } \\
\text { programas que } \\
\text { potencien el } \\
\text { emprendimiento } \\
\text { creativo o las } \\
\text { actividades } \\
\text { creativas a través } \\
\text { de la formulación } \\
\text { estratégica de la } \\
\text { ciudad (Plan } \\
\text { estratégico). }\end{array}$ & $\begin{array}{c}\text { Elaboración } \\
\text { propia a partir } \\
\text { de } \\
\text { ayuntamientos }\end{array}$ \\
\hline & & $\mathrm{Cl} 8$ & $\begin{array}{l}\text { Facilidades para } \\
\text { emprender en } \\
\text { general. }\end{array}$ & $\begin{array}{c}\text { Huidrobo (2002), } \\
\text { Richards and Wilson } \\
(2007)\end{array}$ & $\begin{array}{l}\text { Ventanilla única } \\
\text { administrativa que } \\
\text { facilite el proceso } \\
\text { de puesta en } \\
\text { marcha de } \\
\text { empresas y } \\
\text { proyectos } \\
\text { empresariales. } \\
\text { Programa } \\
\text { Emprende } 3 .\end{array}$ & $\begin{array}{l}\text { Ministerio de } \\
\text { Hacienda y } \\
\text { Administracion } \\
\text { es Públicas }\end{array}$ \\
\hline
\end{tabular}

Fuente: elaboración propia 
Una vez determinados los diferentes indicadores que facilitan el conocimiento de la creatividad de un destino urbano-cultural, se tiene el reto de construir un indicador sintético agregado que resuelva problemas como la agregación de variables expresadas en distintas medidas, la ponderación arbitraria y la duplicidad de información, problemática que ya recogen Somarriba y Pena $(2008,2009 a, 2009 b)$ y proponen una solución. El indicador sintético DP2 determina la distancia que tienen los destinos turísticos urbano-culturales analizados con respecto al peor de todos ellos. Pena (1977), su creador, define el mismo de la siguiente forma:

- $m$ = número de regiones (en este caso destinos turísticos);

- $n$ = número de variables;

- $\quad x i j=$ el valor de la variable $\mathrm{i}$ en la región (en este caso destino turístico) j;

- $\sigma i=$ la desviación típica de la variable i;

- $R^{2} i, i-10,1=$ Coeficiente de Determinación en la Regresión de $X i$, sobre las variables $X_{i}$ 1, Xi-2,, X X , que preceden a Xi. Rodríguez (2012) recuerda que este coeficiente es un número abstracto e independiente de las unidades de medida en que están expresadas las distintas variables.

- $\quad\left(1-R^{2} i, i-10,1\right)=$ Factor corrector. Éste evita duplicidad de información, ya que elimina de los indicadores parciales, la información lineal contenida en los indicadores precedentes (Pena, 1977; Zarzosa, 1996; Somarriba, 2008; Zarzosa, 2009). Es decir, "si expresa la parte de la varianza Xi no explicada por Xi-1, Xi-2,, X1, al multiplicar cada indicador parcial por el correspondiente factor corrector, se deduce la parte ya explicada" (Rodríguez, 2012:5). De esta forma, como advierte Rodríguez (2012), se ponderan las diferencias en la variable i-ésima entre un destino y la base de referencia, por el porcentaje de información (no facilitada por las otras variables), que proporciona esa variable.

El indicador sintético de distancia DP2 se define, para una ciudad turística j-ésima cualquiera, como:

$$
\mathrm{DP}_{2 \mathrm{i}}=\sum_{j=1}^{N_{I}} \frac{d_{i j}}{\sigma_{i}}\left(1-\mathrm{R}_{j, j-1, j-2, \ldots, 1}^{2}\right)
$$

con $i=1,1, n y$, por definición, $R^{2} 1=0$, donde dij=xij-xi(1) es la diferencia entre el valor que toma la variable i-ésima en el destino j y el mínimo de la variable en la situación teórica menos deseable, tomado como base de referencia, como advierte el mismo autor basándose en Pena (1977). 
Siendo el objetivo medir el peso de la creatividad en diferentes destinos urbano-culturales para establecer un ranking, el indicador sintético DP2 recoge contrastes en creatividad, ya que en cada uno los indicadores parciales se toman como base de referencia el valor (xij) correspondiente al que registra el menor valor.

El resultado depende del orden de entrada de las variables. Por tanto, es necesario establecer un orden o jerarquía, en función de la información que cada uno de ellos aporta, es decir, el peso que tienen en el resultado final del índice. En este sentido, el primer indicador parcial incorporado es el que aporta mayor información y, así, sucesivamente (Pena, 1977).

Se parte de una situación inicial determinada por el indicador de Frechet, que se define por la ordenación de las variables en orden descendente, según la correlación con este indicador y, una vez calculado el indicador DP2, se reordenan de acuerdo al valor registrado, hasta obtener una convergencia a un valor en concreto del indicador, denominado criterio de parada (Pena, 1977; Rodríguez, 2012). El proceso termina cuando la distancia entre el nuevo indicador y el del paso anterior es un valor insignificante, en el caso de esta investigación cuando la distancia es inferior a 0,01 .

Como describe Rodríguez (2012), se calcula el indicador de Distancia P2 en una primera fase para cada uno de los destinos turísticos $(n)$, denominado DP2 ${ }^{(1}$. Cuando se estima el indicador para la primera etapa, se recalculan las correlaciones de cada variable con DP2 ${ }^{1}$ y se calcula una nueva reordenación. En este punto, se comprueba si la diferencia entre el DP2(1 y el DP2 $2^{2}$ es inferior a nuestro criterio de parada, que es un valor cercano al 0 . En este caso, se ha establecido en 0,01 tomando como base investigaciones similares en la aplicación de sistemas de indicadores (Luque, Pérez-Moreno, Robles y Rodríguez, 2017; Pena, 1977). A partir de dicho valor se mantiene el orden de entrada de los indicadores que está basado en la correlación de los mismos y el indicador final. El proceso continúa hasta que la diferencia entre dos DP2 sea prácticamente nula, es decir, cuando en dos iteraciones sucesivas se obtiene el mismo valor de índice sintético. Así, se alcanza el resultado definitivo. Este hecho significa que se mantiene el ranking en los indicadores parciales o variables en función de sus respectivas correlaciones.

Se debe indicar que, para el caso del Creacity, se van calculando los índices por fases. Primero por variables, segundo por áreas, tercero por dimensiones y, finalmente, el Creacity global. Para el tratamiento estadístico, así como normalización y la aplicación de índices, se utiliza el programa informático Excel, en su versión 16 y Stata, en su versión 15. 
De cara a acotar los valores finales del indicador Creacity, se opta por normalizar de nuevo el resultado para que todas las dimensiones, así como el global, estuvieran entre 0 y 1, correspondiendo el 0 a la peor calificada y el 1 a la mejor. Para ello, se emplea la siguiente fórmula:

valor del destino en la variable - valor mínimo de la variable

$$
\mathrm{Z}=
$$

$$
\text { valor máximo de la variable - valor mínimo de la variable }
$$

Se debe indicar que los destinos que no tienen datos en alguna de las variables medidas, se valoraron con el mínimo valor existente en esa variable o indicador antes de aplicar el DP2.

Hay que mencionar que la forma en que agrega los indicadores o variables ya lleva implícitos unos pesos para cada indicador, que están relacionados con la influencia que tiene cada uno de ellos en el indicador final. El peso que se asigna a cada uno se calcula en función de la correlación de dicho indicador y el índice final. El valor del "factor corrector" se normaliza para calcular los porcentajes. Por ejemplo, para calcular el peso de las áreas e indicadores creacity espacial, en el caso Espacios culturales y creativos: CE.1. Espacios culturales y creativos tiene un valor del factor corrector de 0,2781; CE.2. Edificios declarados Bien de Interés Cultural; conjuntos históricos y conjuntos monumentales, un valor de 0,7048; y CE.3. Patrimonio cultural con declaración de Patrimonio de la Humanidad, un valor de 1. Por tanto, el mayor peso lo tendía CE.3, con un 50,43\% del total (1,9829), seguido de CE.2 con un 35,54\%, y por último CE. 1. con un $14,02 \%$. Del mismo modo se ha actuado con el resto de ponderaciones.

En relación a los pesos, a la hora de aportar información al índice final (Creacity global), la dimensión que más fuerza posee es la Ambiental (Creacity Ambiental), con un peso del 42,26\% (Tabla 4). Tras ella se sitúa la Institucional (Creacity institucional) con el 36,28\% (Tabla 5) y, finalmente, el Creacity Espacial (Dimensión Espacial), que se queda en el 21,36\% (Tabla 6). 
Tabla 4. Peso de las áreas e indicadores creacity ambiental

\begin{tabular}{|c|c|c|c|}
\hline ÁREA & PESO & INDICADOR & PESO \\
\hline \multirow[t]{6}{*}{$\begin{array}{l}\text { Clases creativas y } \\
\text { producción creativa }\end{array}$} & \multirow[t]{6}{*}{$43,92 \%$} & $\begin{array}{l}\text { CA.1. Actividades } \\
\text { económicas creativas. }\end{array}$ & $22,27 \%$ \\
\hline & & $\begin{array}{l}\text { CA. 2. Peso de las industrias } \\
\text { creativas en la actividad } \\
\text { económica. }\end{array}$ & $1,08 \%$ \\
\hline & & CA. 3. Innovación en marcas. & $25,63 \%$ \\
\hline & & $\begin{array}{l}\text { CA. 4. Innovación en } \\
\text { patentes. }\end{array}$ & $17,33 \%$ \\
\hline & & $\begin{array}{l}\text { CA. 5. Producción científica } \\
\text { en turismo. }\end{array}$ & $20,48 \%$ \\
\hline & & $\begin{array}{l}\text { CA. 6. Calidad del sistema } \\
\text { educativo universitario. }\end{array}$ & $13,20 \%$ \\
\hline \multirow[t]{5}{*}{$\begin{array}{l}\text { Oferta y flujo turístico } \\
\text { cultural }\end{array}$} & \multirow[t]{5}{*}{$25,81 \%$} & $\begin{array}{l}\text { CA. 7. Flujo turístico a } \\
\text { monumentos. }\end{array}$ & $18,40 \%$ \\
\hline & & $\begin{array}{lllll}\text { CA. } 8 . & \text { Flujo turístico a } \\
\text { museos. } & & & \\
\end{array}$ & $25,95 \%$ \\
\hline & & $\begin{array}{l}\text { CA. 9. Calidad e innovación } \\
\text { de la oferta cultural. }\end{array}$ & $5,02 \%$ \\
\hline & & $\begin{array}{l}\text { CA. 10. Actividad de } \\
\text { congresos y reuniones. }\end{array}$ & $25,93 \%$ \\
\hline & & CA. 11. Turismo idiomático. & $24,70 \%$ \\
\hline \multirow{4}{*}{$\begin{array}{l}\text { Apertura, tolerancia, calidad } \\
\text { de vida y participación } \\
\text { ciudadana }^{3}\end{array}$} & \multirow[t]{4}{*}{$30,27 \%$} & CA.12. Homosexualidad. & $18,15 \%$ \\
\hline & & CA.13. Multiculturalidad. & $34,09 \%$ \\
\hline & & 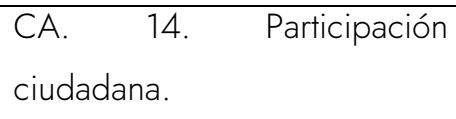 & $26,49 \%$ \\
\hline & & CA. 15. Calidad de vida. & $21,28 \%$ \\
\hline
\end{tabular}

Fuente: elaboración propia

3 Nota: En principio, pudiera parecer que la cuantificación de procesos complejos, como "apertura, tolerancia, calidad de vida y participación", se sustentan en indicadores que parecen demasiado básicos. En este sentido, hay que recordar que el sistema de indicadores propuesto se sustenta sobre información facilitada por diferentes fuentes oficiales y que en estas fuentes no se dispone de una información más detallada, como sería deseable. Este sistema de indicadores ha sido testado y verificado por un panel de expertos garantizando su validez. 
Tabla 5. Peso de las áreas e indicadores creacity institucional

\begin{tabular}{|c|c|c|c|}
\hline ÁREA & PESO & INDICADOR & PESO \\
\hline \multirow[t]{2}{*}{ Gobierno abierto } & \multirow[t]{2}{*}{$22,19 \%$} & Cl.1. Transparencia administrativa. & $50,00 \%$ \\
\hline & & Cl. 2. Administración electrónica. & $50,00 \%$ \\
\hline \multirow[t]{2}{*}{$\begin{array}{l}\text { Gestión estratégica del } \\
\text { turismo }\end{array}$} & \multirow[t]{2}{*}{$25,08 \%$} & $\begin{array}{l}\text { Cl. 3. Existencia y consistencia de una } \\
\text { visión estratégica del turismo. }\end{array}$ & $50,00 \%$ \\
\hline & & Cl. 4. Clustering. & $50,00 \%$ \\
\hline Talento institucional & $24,77 \%$ & $\begin{array}{l}\text { Cl. 5. Presencia de talento en los } \\
\text { órganos de gestión turística. }\end{array}$ & $100,00 \%$ \\
\hline \multirow[t]{3}{*}{ Estimulación creativa } & \multirow[t]{3}{*}{$27,96 \%$} & Cl. 6. Imagen destino creativo. & $35,99 \%$ \\
\hline & & Cl. 7. Emprendimiento creativo. & $35,34 \%$ \\
\hline & & $\begin{array}{l}\text { Cl. 8. Facilidades para emprender en } \\
\text { general. }\end{array}$ & $28,67 \%$ \\
\hline
\end{tabular}

Fuente: elaboración propia

Tabla 6. Peso de las áreas e indicadores creacity espacial

\begin{tabular}{|c|c|c|c|}
\hline ÁREA & PESO & INDICADOR & PESO \\
\hline \multirow[t]{3}{*}{$\begin{array}{l}\text { Espacios culturales y } \\
\text { creativos }\end{array}$} & \multirow[t]{3}{*}{$25,14 \%$} & $\begin{array}{l}\text { CE.1. Espacios culturales y } \\
\text { creativos. }\end{array}$ & $14,02 \%$ \\
\hline & & $\begin{array}{l}\text { CE.2. Edificios declarados Bien de } \\
\text { Interés Cultural; conjuntos históricos } \\
\text { y conjuntos monumentales. }\end{array}$ & $35,54 \%$ \\
\hline & & $\begin{array}{l}\text { CE.3. Patrimonio cultural con } \\
\text { declaración de Patrimonio de la } \\
\text { Humanidad. }\end{array}$ & $50,43 \%$ \\
\hline \multirow[t]{2}{*}{$\begin{array}{l}\text { Centros académicos } \\
\text { que fomenten la } \\
\text { creatividad }\end{array}$} & \multirow[t]{2}{*}{$28,99 \%$} & $\begin{array}{l}\text { CE.4. Escuelas de Música; escuelas } \\
\text { de Idiomas, escuelas de Danza y } \\
\text { escuelas de Teatro. }\end{array}$ & $36,51 \%$ \\
\hline & & $\begin{array}{l}\text { CE.5. Estudios asociados a las áreas } \\
\text { académicas de Arte e } \\
\text { Interpretación; } \\
\text { Publicidad; Comunicación y } \\
\text { Turismo e Idiomas. }\end{array}$ & $33,15 \%$ \\
\hline
\end{tabular}


Tabla 6. Continuación

\begin{tabular}{|c|c|c|c|}
\hline $\begin{array}{l}\text { Centros académicos } \\
\text { que fomenten la } \\
\text { creatividad }\end{array}$ & $28,99 \%$ & $\begin{array}{l}\text { CE.6. Centros tecnológicos y de } \\
\text { innovación. }\end{array}$ & $30,33 \%$ \\
\hline \multirow[t]{3}{*}{$\begin{array}{l}\text { Establecimientos } \\
\text { turísticos de } \\
\text { singularidad creativa }\end{array}$} & \multirow[t]{3}{*}{$17,18 \%$} & $\begin{array}{l}\text { CE.7. Restaurantes ubicados en } \\
\text { edificios de singularidad } \\
\text { arquitectónica. }\end{array}$ & $36,26 \%$ \\
\hline & & $\begin{array}{l}\text { CE.8. Restaurantes con estrellas } \\
\text { Michelín. }\end{array}$ & $34,29 \%$ \\
\hline & & $\begin{array}{l}\text { CE.9. Alojamientos ubicados en } \\
\text { edificios de gran singularidad } \\
\text { arquitectónica. }\end{array}$ & $29,35 \%$ \\
\hline \multirow[t]{2}{*}{$\begin{array}{l}\text { Conectividad física y } \\
\text { digital }\end{array}$} & \multirow[t]{2}{*}{$28,69 \%$} & $\begin{array}{l}\text { CE.10. Accesibilidad y movilidad } \\
\text { urbana en relación al turismo. }\end{array}$ & $50,00 \%$ \\
\hline & & $\begin{array}{l}\text { CE.11. Accesibilidad digital. } \\
\text { Adecuación de la web que } \\
\text { representa al destino a las } \\
\text { necesidades del mercado. }\end{array}$ & $50,00 \%$ \\
\hline
\end{tabular}

Fuente: elaboración propia

\section{Resultados}

En esta parte del artículo se afronta la aplicación del índice Creacity a los veinte destinos turísticos urbano-culturales más importantes de España. A partir de este momento, se mide el peso que tiene la creatividad en el ecosistema turístico local, a través de las tres dimensiones (espacial, ambiental e institucional) ya explicadas anteriormente.

Una vez que el índice sintético agregado Creacity fue aplicado a los destinos elegidos (Tabla 7), los resultados muestran que son seis las ciudades con un valor igual o superior al 0,50 (Barcelona, Madrid, Santiago de Compostela, Valencia, Granada y Bilbao), lo que representa el $30 \%$ del total. La mediana de los veinte destinos analizados es igual a 0,3683 y la media aritmética a 0,4098. Estos resultados permiten afirmar que el 70\% de los destinos urbanoculturales suspenden, al no alcanzar la mitad del límite de la valoración, tomando como referencia el índice 1 (máxima puntuación). 
El resultado a nivel dimensional puede apreciarse en el Creacity espacial. Sólo cuatro ciudades alcanzan o superan el 0,50 (Santiago de Compostela, Madrid, Granada y Barcelona) en creatividad espacial, lo que equivale al $20 \%$ de las ciudades analizadas. Los veinte casos analizados hacen que la mediana del índice agregado de la dimensión espacial se sitúe en 0,2413 y la media aritmética en 0,2839. Dentro de la dimensión ambiental, el número de ciudades que superan dicha marca se eleva hasta cinco (Barcelona, Madrid, Santiago de Compostela, Toledo y Valencia), lo que representa un 25\% de la muestra. O lo que es lo mismo, el $75 \%$ de los destinos estudiados no consiguen generar un ambiente creativo turístico. En esta dimensión, la mediana es de 0,2387 y la media de 0,3326. Por último, el Creacity institucional depara el mejor resultado entre los veinte. Son nueve las ciudades que consiguen alcanzar o superar el 0,50 (Bilbao, Valencia, Barcelona, Gijón, Zaragoza, Granada, Sevilla, San Sebastián y Madrid). Por tanto, se afirma que el $45 \%$ de los destinos analizados aprueban en creatividad institucional. La mediana, en esta dimensión, es de 0,4796 y la media aritmética de 0,4407. Como se puede advertir, suponen los valores más altos, con cierta diferencia, de las tres dimensiones Creacity.

Tabla 7. Resultados de la aplicación del índice creacity

\begin{tabular}{|l|l|l|l|l|l|l|l|l|}
\hline CIUDAD & $\begin{array}{l}\text { CREACITY } \\
\text { GLOBAL }\end{array}$ & $\begin{array}{l}\text { RAN- } \\
\text { KING }\end{array}$ & $\begin{array}{l}\text { CREACITY } \\
\text { ESPACIAL }\end{array}$ & $\begin{array}{l}\text { RAN- } \\
\text { KING }\end{array}$ & $\begin{array}{l}\text { CREACITY } \\
\text { AMBIENTAL }\end{array}$ & $\begin{array}{l}\text { RAN- } \\
\text { KING }\end{array}$ & $\begin{array}{l}\text { CREACITY } \\
\text { INSTITUTIONAL }\end{array}$ & $\begin{array}{l}\text { RAN- } \\
\text { KING }\end{array}$ \\
\hline BARCELONA & 1 & $1^{\circ}$ & 0,5189 & $4^{\circ}$ & 1 & $1^{\circ}$ & 0,9551 & $3^{\circ}$ \\
\hline MADRID & 0,8498 & $2^{\circ}$ & 0,6068 & $2^{\circ}$ & 0,9665 & $2^{\circ}$ & 0,5536 & $9^{\circ}$ \\
\hline SANTIAGO & 0,7946 & $3^{\circ}$ & 1 & $1^{\circ}$ & 0,7586 & $3^{\circ}$ & 0,3788 & $13^{\circ}$ \\
\hline VALENCIA & 0,7616 & $4^{\circ}$ & 0,3702 & $7^{\circ}$ & 0,5931 & $5^{\circ}$ & 0,9721 & $2^{\circ}$ \\
\hline GRANADA & 0,5940 & $5^{\circ}$ & 0,5462 & $3^{\circ}$ & 0,3661 & $7^{\circ}$ & 0,7013 & $6^{\circ}$ \\
\hline BILBAO & 0,5874 & $6^{\circ}$ & 0,1263 & $13^{\circ}$ & 0,3653 & $8^{\circ}$ & 1 & $1^{\circ}$ \\
\hline SEVILLA & 0,4946 & $7^{\circ}$ & 0,4438 & $6^{\circ}$ & 0,2327 & $11^{\circ}$ & 0,6936 & $7^{\circ}$ \\
\hline S. SEBASTIAN & 0,4799 & $8^{\circ}$ & 0,4592 & $5^{\circ}$ & 0,2811 & $9^{\circ}$ & 0,5853 & $8^{\circ}$ \\
\hline ZARAGOZA & 0,3858 & $9^{\circ}$ & 0,1386 & $12^{\circ}$ & 0,1723 & $12^{\circ}$ & 0,7239 & $5^{\circ}$ \\
\hline TOLEDO & 0,3707 & $10^{\circ}$ & 0,3311 & $8^{\circ}$ & 0,6094 & $4^{\circ}$ & 0 & $20^{\circ}$ \\
\hline ALICANTE & 0,3659 & $11^{\circ}$ & 0,0233 & $18^{\circ}$ & 0,4395 & $6^{\circ}$ & 0,4289 & $12^{\circ}$ \\
\hline SALAMANCA & 0,3648 & $12^{\circ}$ & 0,3002 & $9^{\circ}$ & 0,2447 & $10^{\circ}$ & 0,4605 & $11^{\circ}$ \\
\hline MALAGA & 0,2765 & $13^{\circ}$ & 0,0959 & $14^{\circ}$ & 0,1583 & $14^{\circ}$ & 0,4987 & $10^{\circ}$ \\
\hline GIION & 0,2670 & $14^{\circ}$ & 0 & $20^{\circ}$ & 0,0004 & $19^{\circ}$ & 0,7425 & $4^{\circ}$ \\
\hline SANTANDER & 0,2195 & $15^{\circ}$ & 0,2515 & $10^{\circ}$ & 0,0935 & $15^{\circ}$ & 0,3197 & $15^{\circ}$ \\
\hline CORDOBA & 0,2087 & $16^{\circ}$ & 0,2312 & $11^{\circ}$ & 0,0796 & $16^{\circ}$ & 0,3249 & $14^{\circ}$ \\
\hline
\end{tabular}


Tabla 7. Continuación

\begin{tabular}{|l|l|l|l|l|l|l|l|l|}
\hline CIUDAD & $\begin{array}{l}\text { CREACITY } \\
\text { GLOBAL }\end{array}$ & $\begin{array}{l}\text { RAN- } \\
\text { KING }\end{array}$ & $\begin{array}{l}\text { CREACIT } \\
\text { Y } \\
\text { ESPACIA } \\
\text { L }\end{array}$ & $\begin{array}{l}\text { RAN- } \\
\text { KING }\end{array}$ & $\begin{array}{l}\text { CREACITY } \\
\text { AMBIENTAL }\end{array}$ & $\begin{array}{l}\text { RAN- } \\
\text { KING }\end{array}$ & $\begin{array}{l}\text { CREACITY } \\
\text { INSTITUTIONAL }\end{array}$ & $\begin{array}{l}\text { RAN- } \\
\text { KING }\end{array}$ \\
\hline BURGOS & 0,0792 & $17^{\circ}$ & 0,0047 & $19^{\circ}$ & 0,1715 & $13^{\circ}$ & 0,0552 & $17^{\circ}$ \\
\hline LA CORUNA & 0,0672 & $18^{\circ}$ & 0,0788 & $16^{\circ}$ & 0,0463 & $18^{\circ}$ & 0,1250 & $16^{\circ}$ \\
\hline OVIEDO & 0,0289 & $19^{\circ}$ & 0,0587 & $17^{\circ}$ & 0,0741 & $17^{\circ}$ & 0,0095 & $18^{\circ}$ \\
\hline LEON & 0 & $20^{\circ}$ & 0,0935 & $15^{\circ}$ & 0 & $20^{\circ}$ & 0,0026 & $19^{\circ}$ \\
\hline
\end{tabular}

Fuente: elaboración propia

A continuación, se analizan las características y valoraciones de los ecosistemas turísticos creativos, considerando como tales aquellos destinos urbano-culturales que, tras ser sometidos al índice Creacity, superan el 0,50 de valor. Para ello, resultan bastantes descriptivas las matrices creativas, gráficos que permiten conocer visualmente los puntos fuertes (ventajas creativas) y débiles (desventajas creativas) del sistema turístico. Todo esto partiendo de los resultados de las áreas dimensinales del Creacity (Tabla 8).

El destino urbano-cultural más creativo de los analizados es Barcelona, líder en el índice sintético Creacity, ocupando la cuarta plaza en el Creacity espacial, la primera posición en el Creacity ambiental y, por último, queda en tercer lugar en el Creacity institucional. Las dimensiones con mayor peso (ambiental e institucional) consolidan la puntuación final, lo que la sitúa en primer lugar frente al resto.

Esta ciudad presenta ventajas creativas en siete de las once áreas (Figura 1). Espacialmente, Barcelona tiene un magnífico índice en Conectividad física y digital $(0,9052)$, el único en esta dimensión y en el que sólo es superada por Madrid. En el Creacity ambiental se encuentran Clases creativas y producción creativa $(0,8724)$; Oferta y flujo turístico cultural $(0,7828)$; Apertura, tolerancia, calidad de vida y participación ciudadana (1). Dentro de la dimensión institucional sus ventajas están en Gobierno abierto (0,9387); Gestión estratégica del turismo (1) y Estimulación creativa $(0,5823)$. Las desventajas creativas, y por tanto áreas de crecimiento, son Espacios culturales y creativos $(0,2211)$; Centros académicos que fomenten la creatividad $(0,3462)$; Establecimientos turísticos de singularidad creativa $(0,4394)$ y Talento institucional $(0)$. 
Tabla 8. Resumen de los índices de las áreas creacity

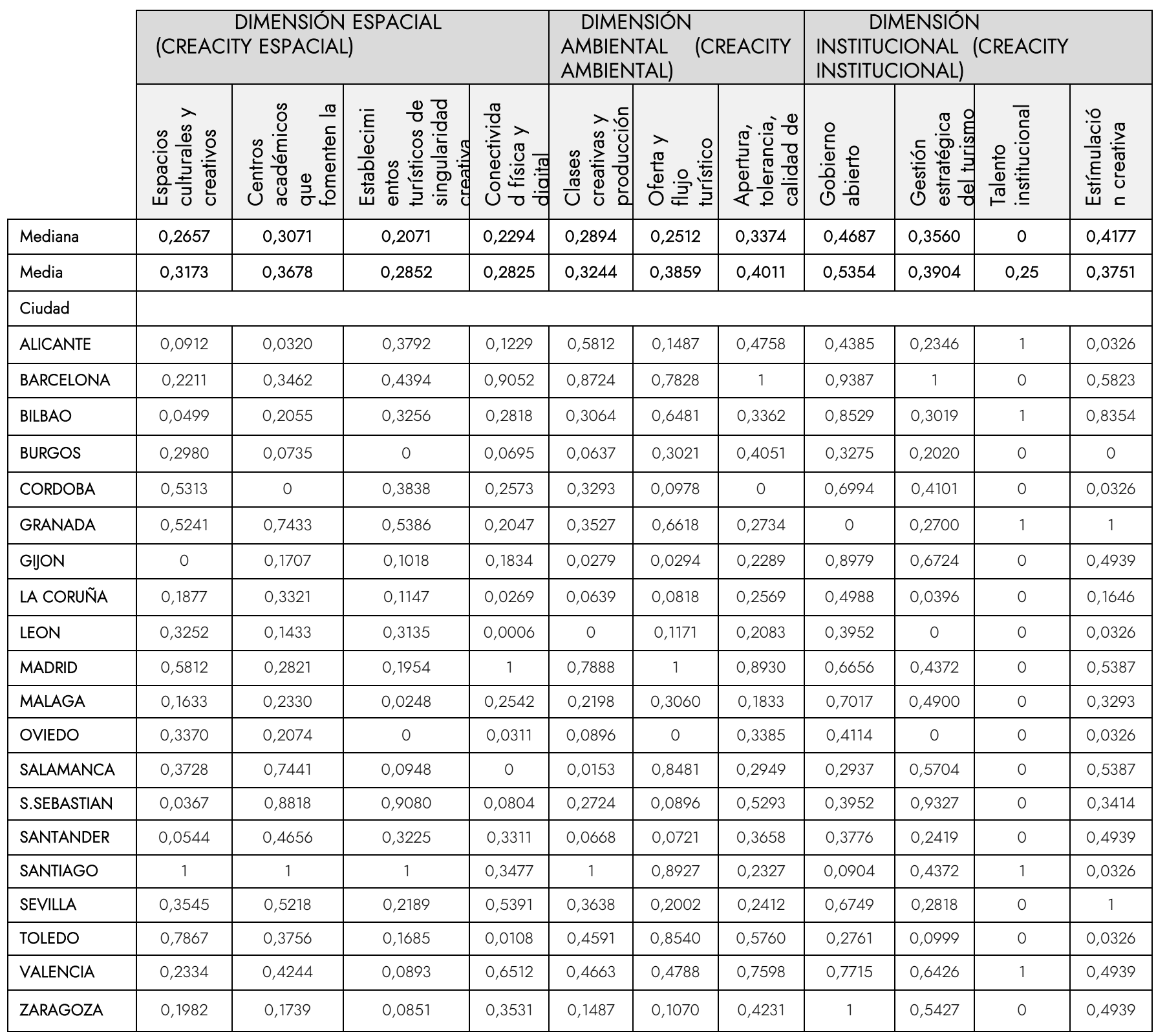

Fuente: elaboración propia

La segunda posición es ocupada por Madrid, con un Creactity global de 0,8498. Este destino consigue este valor después de obtener un 0,6068 (segunda plaza) en la dimensión espacial, un 0,9665 (segunda posición) en la dimensión ambiental y un 0,5536 (novena plaza) en la dimensión institucional. Madrid, por tanto, se puede afirmar que es un destino turístico con altas dosis de creatividad, constituyendo también un ecosistema turístico creativo alimentando, fundamentalmente, al igual que Barcelona, desde las áreas que miden el ambiente creativo. 
Figura 1. Matriz creativa del destino Barcelona

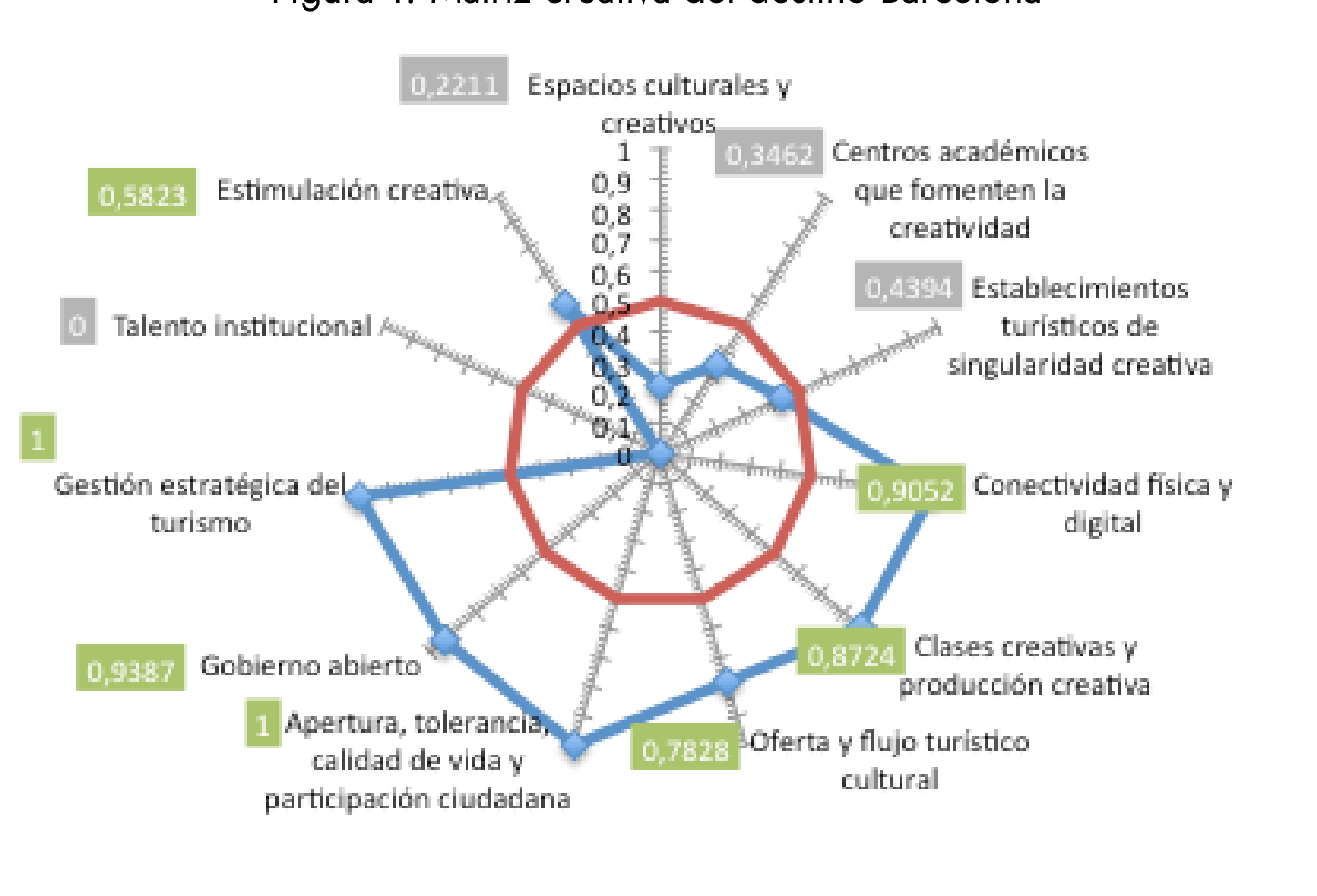

Fuente: elaboración propia

Este destino también plantea como áreas aventajadas siete de las once (Figura 2). En la dimensión espacial, se encuentran Espacios culturales y creativos $(0,5812)$ y Conectividad física y digital (1). Se observa que, a pesar de la ponderación demográfica, Madrid obtiene un 0,5812 en el área que mide los espacios de vocación creativa del destino. El mayor número de ventajas aparece en el Creacity ambiental, con una destacada valoración en Clases creativas y producción creativa (0,7888); Oferta y flujo turístico cultural (1) y Apertura, tolerancia, calidad de vida y participación ciudadana (0,8930). En el ámbito institucional, es competitiva en Gobierno abierto $(0,6656)$ y, en menor medida, en Estimulación creativa $(0,5387)$. Las desventajas creativas de Madrid se localizan en Centros académicos que fomenten la creatividad $(0,2821)$, consecuencia de la ya mencionada ponderación por habitante; Establecimientos turísticos de singularidad creativa $(0,1954)$; Gestión estratégica del turismo $(0,4372)$ y Talento institucional $(0)$. 


\section{Figura 2. Matriz creativa del destino Madrid}

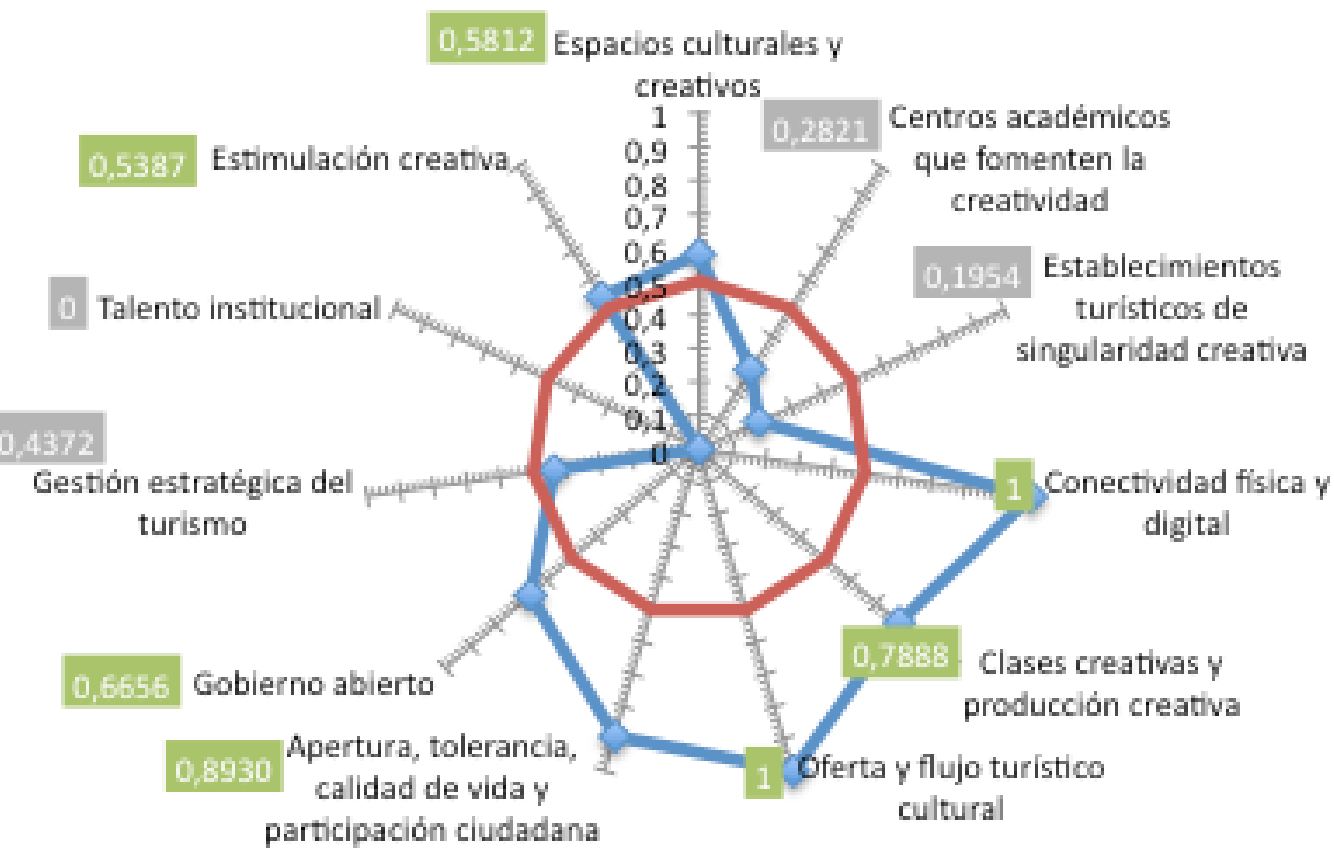

Fuente: elaboración propia

En el puesto tres de este ranking de creatividad turística se encuentra Santiago de Compostela $(0,7946)$, una ciudad pequeña (menos de 100000 habitantes) que consigue estar por encima de otras mucho más pobladas (Valencia, Sevilla, Zaragoza o Málaga, por ejemplo). Partiendo de una importante creatividad espacial (primera posición y a cierta distancia del segundo), consigue configurar un ecosistema turístico creativo, afianzado en un buen resultado $(0,7586)$ en la dimensión ambiental (tercera plaza). No siendo un lastre el índice generado en la creatividad institucional (0,3788 y decimotercera posición) para su buena posición global.

La capital gallega exhibe ventajas creativas en seis áreas del Creacity (Figura 3). En la dimensión espacial, obtiene las máximas valoraciones en Espacios culturales y creativos (1); Centros académicos que fomenten la creatividad (1) y Establecimientos turísticos de singularidad creativa (1). Dentro del ambiente creativo, sus puntos fuertes aparecen en Clases creativas y producción creativa (1), así como en Oferta y flujo turístico cultural $(0,8927)$, obsérvese que estos resultados las sitúan como ventajas muy sólidas. En el Creacity institucional, su ventaja es en Talento institucional (1). En su defecto, como desventajas se localizan cinco. Aquí se hallan Conectividad física y digital $(0,3477)$, si se corrige este comportamiento ampliaría la distancia aún más con respecto al segundo clasificado en la dimensión espacial; Apertura, tolerancia, calidad de vida y 
participación ciudadana (0,2327); Gobierno abierto (0,0904); Gestión estratégica del turismo $(0,4372)$ y Estimulación creativa $(0,0326)$.

Figura 3. Matriz creativa del destino Santiago de Compostela

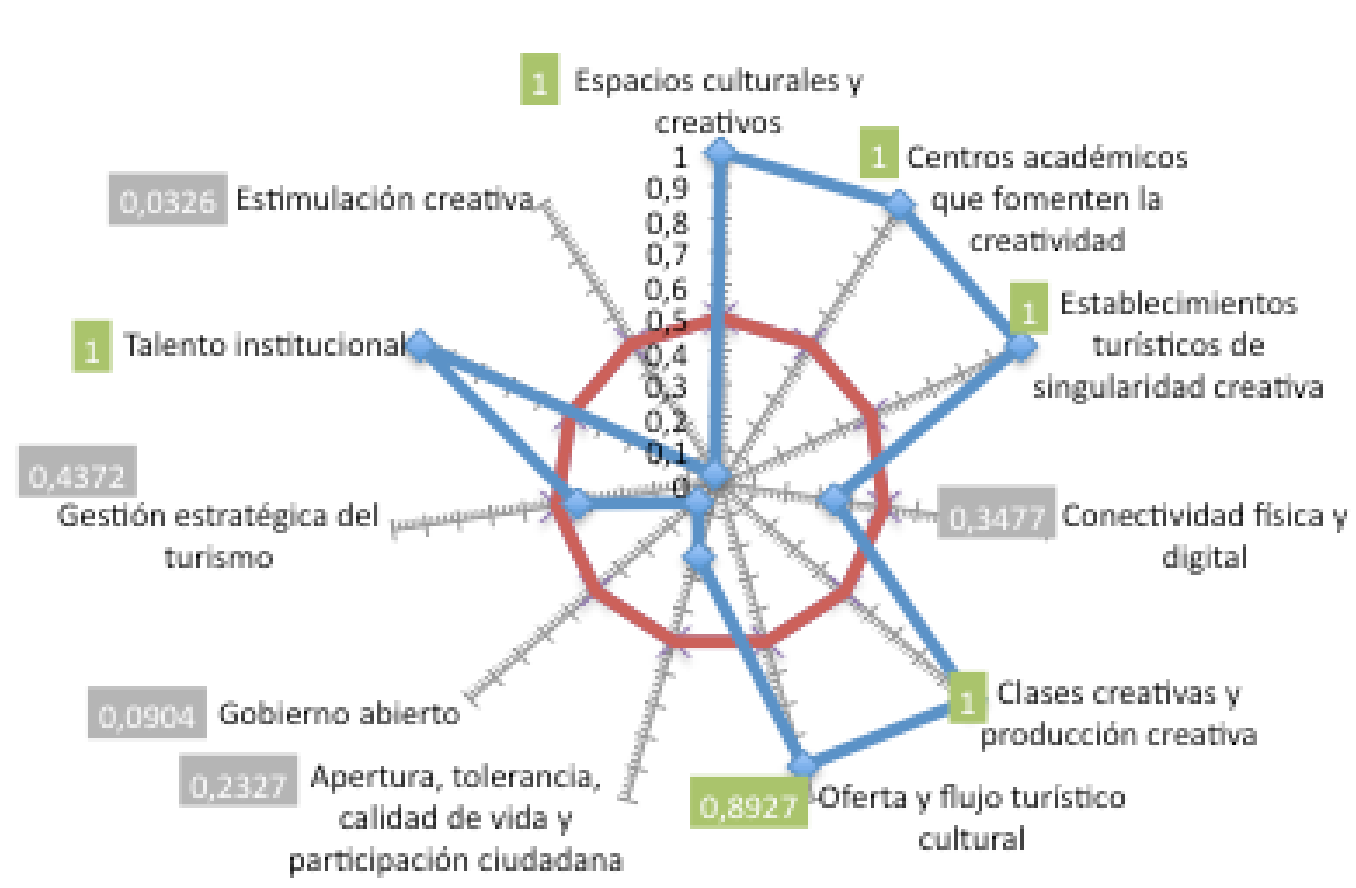

Fuente: elaboración propia

Valencia es un destino turístico de gran población que ocupa la cuarta plaza $(0,7616)$. En la dimensión espacial obtiene su peor valor (0,3702), lo que la lleva a la séptima posición. Consigue un índice Creacity ambiental de 0,5931 (quinta plaza) y, por último, uno institucional de 0,9721. Valor éste último que, teniendo en cuenta su peso (36,38 \%), contribuye notablemente al índice definitivo alcanzado, a lo que ayuda también su valoración en el Creacity parcial más importante.

El sistema turístico local valenciano muestra ventajas creativas en cinco áreas (Figura 4), repartidas también en las tres dimensiones, aunque concentradas en la institucional, como es lógico a tenor del resultado ya expuesto. En el Creacity espacial es Conectividad física y digital $(0,6512)$ el área en la que se aparta momentáneamente de su discreto resultado dimensional. Dentro del ambiente creativo posee una buena ventaja en Apertura, tolerancia, calidad de vida y participación ciudadana $(0,7598)$. Sus áreas aventajadas en el ámbito institucional son Gobierno abierto (0,7715); Gestión estratégica del turismo $(0,6426)$ y Talento institucional (1). Por el contrario, las desventajas se encuentran en Espacios culturales y creativos $(0,2334)$; Centros académicos que fomenten la creatividad $(0,4244)$; Establecimientos turísticos de singularidad 
creativa (0,0893); Clases creativas y producción creativa $(0,4663)$; Oferta y flujo turístico cultural $(0,4788)$ y Estimulación creativa $(0,4939)$. Desventajas identificadas con las dimensiones espacial (3), ambiental (2) e institucional (1) por este orden.

Figura 4. Matriz creativa del destino Valencia

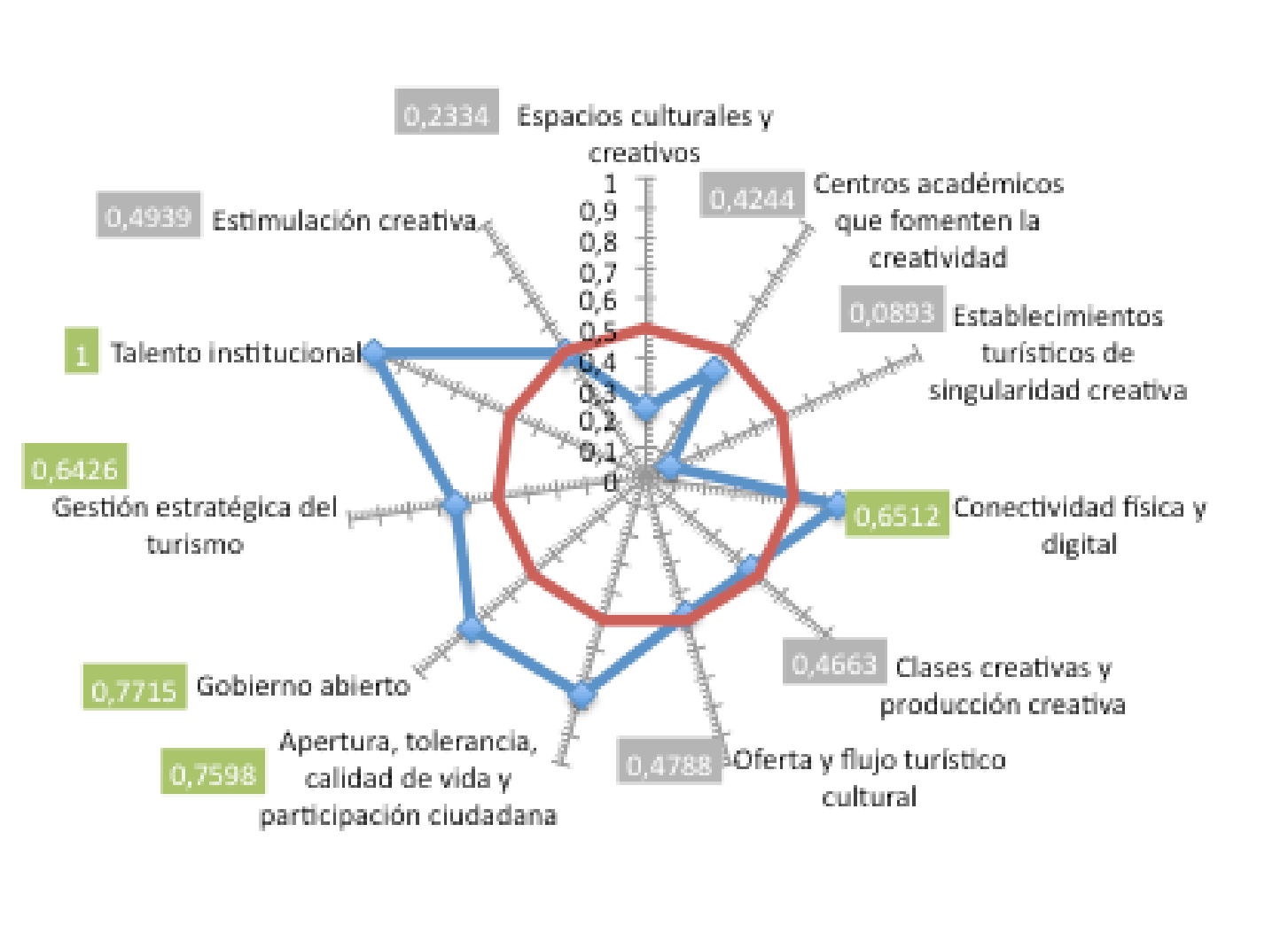

Fuente: elaboración propia

El resultado del Creacity aplicado en Granada la sitúa, a nivel global, en quinta plaza $(0,5940)$. La ciudad nazarí tiene un índice de 0,5462 (tercera posición) en creatividad turística espacial y 0,3661 (puesto siete) en el ambiente creativo turístico. En la segunda dimensión en importancia, la institucional, el valor es 0,7013 , lo que significa la sexta plaza.

Al igual que Valencia, Granada presenta también seis áreas como ventajas creativas (Figura 5) y, al mismo tiempo, distribuidas entre todas las dimensiones. De esta forma, en el Creacity espacial tiene tres, como son Espacios culturales y creativos (0,5241); Centros académicos que fomenten la creatividad $(0,7433)$; y Establecimientos turísticos de singularidad creativa $(0,5386)$. En el Creacity ambiental, su peor resultado dimensional, contempla el área Oferta y flujo turístico creativo $(0,6618)$. Por último, en la dimensión institucional, se encuentran Talento institucional (1) y Estimulación creativa (1), con magníficos resultados. Sus desventajas creativas son Conectividad física y digital $(0,2047)$, producto, sobre todo, de su deficiente 
comunicación ferroviaria y escasez de vuelos, así como Clases creativas y producción creativa (0,3527); Apertura, tolerancia, calidad de vida y participación ciudadana $(0,2734)$; Gobierno abierto (0) y Gestión estratégica del turismo (0,2700). Dos resultados, estos últimos, que impiden que Granada alcance una mayor puntuación en el Creacity institucional, siendo ésta, por otra parte, la dimensión mejor valorada. No obstante, las áreas menos favorecidas también están repartidas dimensionalmente.

\section{Figura 5. Matriz creativa del destino Granada}

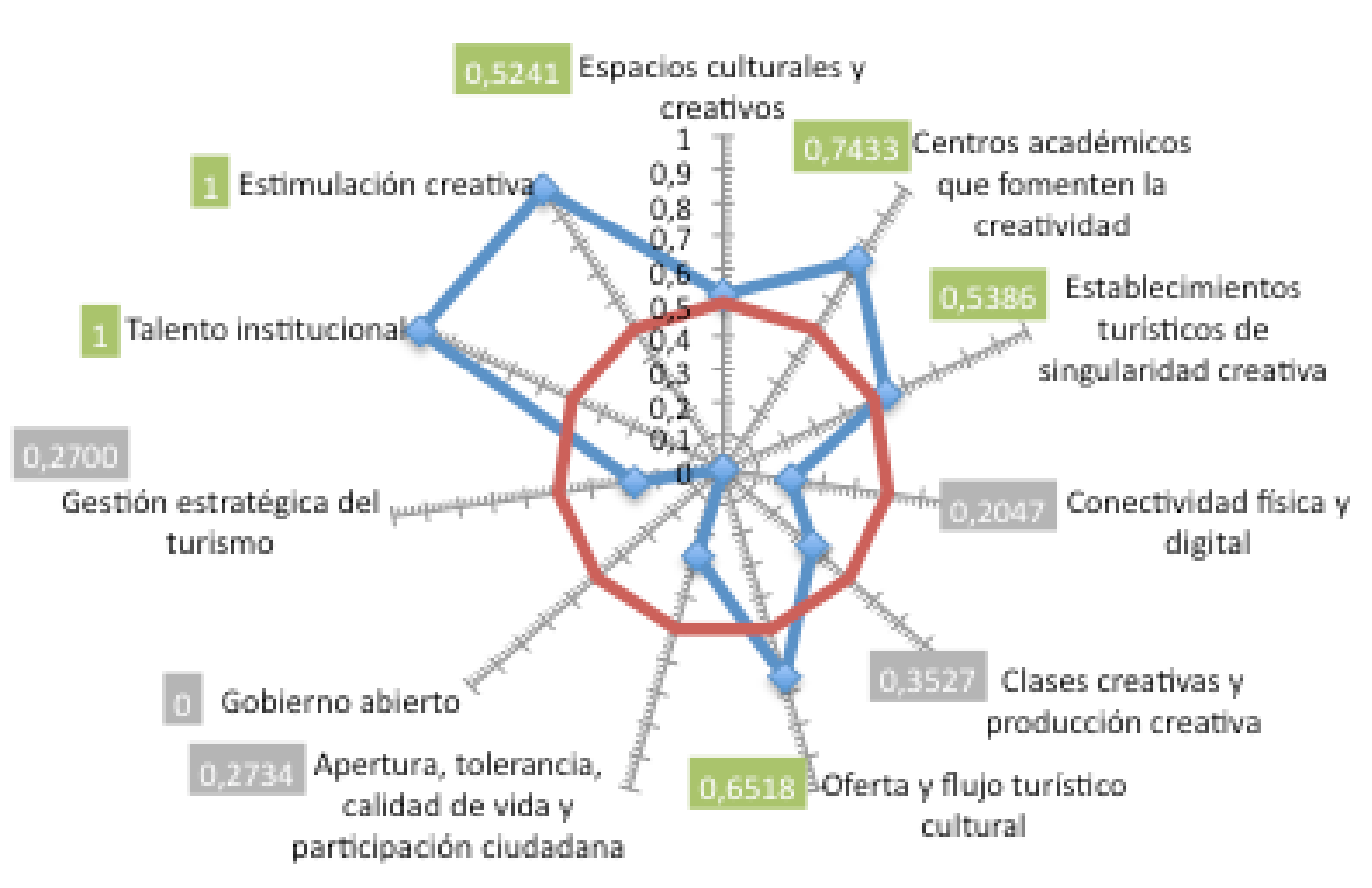

Fuente: elaboración propia

Bilbao es el último destino turístico que consigue superar el 0,50 en el Creacity global, obteniendo un 0,5874 (sexta posición). Esta ciudad construye su creatividad a partir de una excelente posición en el Creacity institucional (primera plaza), lo que lleva a considerarlo como institucionalmente creativo. Su ambiente creativo turístico $(0,3653)$ se sitúa en octava plaza, pero su baja creatividad espacial turística desciende hasta el decimotercer emplazamiento $(0,1263)$. Todo ello lleva a considerar Bilbao como un ecosistema turístico creativo no afianzado, débil, con una sola dimensión por encima del medio punto.

El destino turístico Bilbao tiene cuatro áreas como ventajas creativas (Figura 6), éstas se concentran en dos dimensiones. Dentro del Creacity ambiental aparece Oferta y flujo turístico cultural $(0,6481)$, consecuencia directa del peso del Museo Guggenheim. Pero es en la dimensión institucional en la que se encuentran el resto de áreas. En este Creacity parcial 
destacan excelentes resultados en Gobierno abierto $(0,8529)$, Talento institucional (1) y Estimulación creativa $(0,8354)$. Por tanto, Bilbao posee sus ventajas creativas en las dimensiones con mayor peso. Sus desventajas creativas son Espacios culturales y creativos $(0,0499)$; Centros académicos que fomenten la creatividad $(0,2055)$; Establecimientos turísticos y singularidad creativa $(0,3256)$; Conectividad física y digital $(0,2818)$; Clases creativas y producción creativa (0,3064); Apertura, tolerancia, calidad de vida y participación ciudadana (0,3362) y Gestión estratégica del turismo $(0,3019)$. Estas desventajas impiden generar un espacio creativo turístico al mismo tiempo que fortalecer su ambiente creativo y, por tanto, lastran la posibilidad de crecer como ecosistema turístico creativo.

Figura 6. Matriz creativa del destino Bilbao

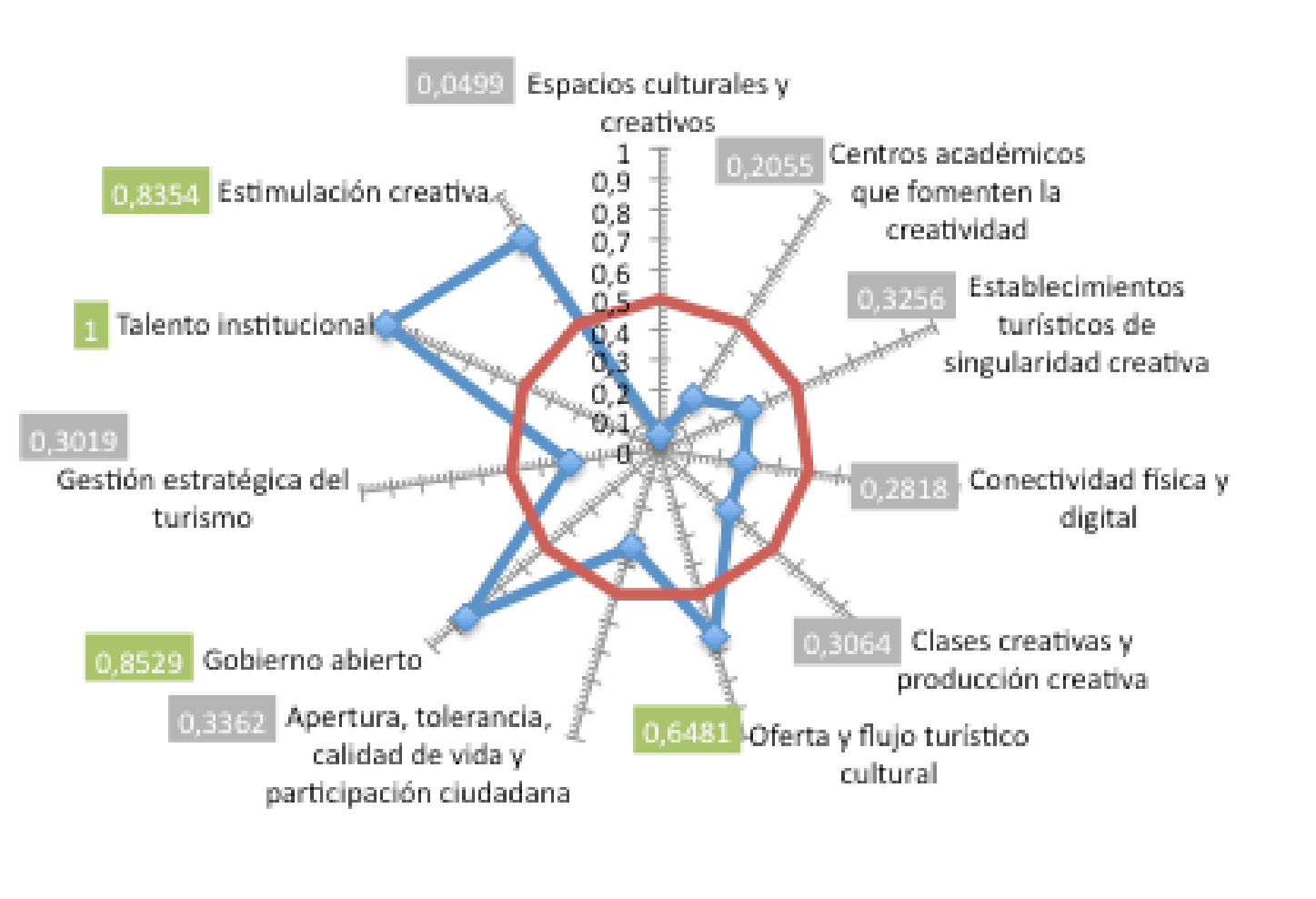

Fuente: elaboración propia

\section{Discusión y conclusiones}

El ecosistema turístico creativo es una propuesta de destino que utiliza como fuente de energía intelectual la creatividad y ésta empapa a cada uno de sus componentes. Todo ello partiendo de una creatividad individual que, gracias a la interacción colectiva termina fusionándose en una creatividad global que abastece a todo el sistema turístico local. Por tanto, la persona y su capacidad creativa innata en su condición humana actúan nuclearmente en el sistema generado. 
Sus tres dimensiones (espacial, ambiental e institucional) se retroalimentan, dando importancia al espacio (concebido y creado por el ser humano), ambiente (generado y alimentado por el ser humano) y gobierno (propiciado y gestionado por el ser humano) como triángulo desde el que sustentar este modelo sistémico. Asimismo, este ser humano epicentro de todas las dimensiones corresponde a la persona creativa, cuya personalidad fomenta la creatividad y, por ende, el desarrollo creativo del entorno en el que se ubica (Cskszentmihalyi, 1996). El ecosistema turístico creativo no constituye en sí mismo un alegato en contra del destino turístico inteligente (smart destination), sino más bien una propuesta que cree en la creatividad como detonador humano para la mejora de los sistemas socioeconómicos que viven en los territorios y que contempla la tecnología como un gran aliado.

El índice sintético Creacity se establece como una novedosa herramienta que hace posible la medición de la creatividad en destinos urbano-culturales. 34 indicadores apoyan su validez y dan forma a las tres dimensiones expuestas (ambiental, espacial e institucional). Estas dimensiones sirven, a su vez, para generar índices relativos que miden la creatividad espacial (áreas físicas facilitadoras del desarrollo creativo), la creatividad ambiental (la densidad del ambiente creativo con la presencia de clases creativas) o la institucional (la dinamización que estimule el pensamiento divergente y la generación de ideas a través de un marco propiciado por los actores públicos y gubernamentales) de un destino turístico. Se mide, por tanto, la creatividad del destino a través de los tres pilares, basados en el carácter multidisciplinar que caracteriza a la actividad turística y, a su vez, diseñados desde una perspectiva holística como requieren las metodologías destinadas a evaluar la creatividad (Florida, 2002; Hollanders \& van Cruysen, 2009).

Por otro lado, el empleo del DP2 para la obtención de este índice constituye un hito en la investigación turística, habiéndose empleado hasta la fecha en investigaciones asociadas a la calidad de vida, fundamentalmente. Este indicador sintético agregado marca la distancia al peor resultado lo que supone una diferencia metodológica con respecto a los empleados con anterioridad.

Como se ha expuesto en el apartado anterior, la creatividad no constituye un elemento esencial en los destinos turísticos urbano-culturales, al no alcanzar una valoración media de 0,5 en el índice Creacity, siendo Barcelona y Madrid las dos ciudades mejor posicionadas. En total, sólo seis de los veinte destinos analizados son considerados ecosistemas creativos, aunque en distintos niveles de desarrollo. No obstante, es necesario aclarar que la densidad demográfica 
no es un elemento determinante para un ecosistema turístico, ya que ciudades como Santiago de Compostela, Granada o Bilbao están bien posicionadas en el ranking, al contrario de lo que ocurre en el índice sintético desarrollado por Hollanders y van Cruysen (2009), quienes relacionan una mayor densidad de la población con un mayor nivel educativo al existir infraestructuras e instituciones orientadas a tal fin. Algunas de las ventajas creativas que poseen Barcelona y Madrid, como la Conectividad física y digital, las Clases creativas y Producción Creativa, constituyen ámbitos determinantes para lograr la excelencia.

Por otra parte, cabe destacar que, aunque las tres dimensiones contribuyen a la competitividad de las ciudades analizadas, es el subíndice ambiental el que posee una mayor correlación lineal entre creatividad en los destinos turísticos y su competitividad. De hecho, son varios los trabajos que coinciden en la importancia de este aspecto a la hora de conocer la creatividad en un territorio. En concreto, Florida (2002) destaca el talento personal que reside en éste como uno de los tres grandes elementos para conocer su creatividad. Por otro lado, las clases creativas y la producción creativa es el área que más peso tiene en la constitución del creacity ambiental, coincidiendo con la tónica habitual de medir el talento personal a través de la presencia de industrias creativas en el desarrollo de indicadores de creatividad (Florida, 2002; Florida et al., 2015; Florida \& Tinagli, 2004; Hollanders \& van Cruysen, 2009; Hui et al., 2005).

No obstante, no pueden obviarse ninguna de las dimensiones a la hora de trabajar en la gestión de destinos urbano creativos. Aunque el creacity institucional ocupa el segundo lugar por su peso en el sistema de indicadores, contribuye notoriamente a posicionar las ciudades analizadas en el ranking. De hecho, la gestión turística y la transparencia gubernamental son áreas con una gran influencia en esta dimensión. El ejemplo de esto está en Bilbao, ocupando el puesto número seis del ranking Creacity gracias su primera posición en la dimensión institucional. La gobernanza y la transparencia en la gestión de los destinos turísticos son procesos indispensables de un gobierno abierto (Ramírez-Alujas, 2014).

Por último, la dimensión espacial o creacity espacial, culmina el índice creacity mediante la evaluación del espacio creativo, siendo éste uno de los tres grandes pilares de la creatividad en los destinos urbano culturales que ha sido tratado por diversos trabajos. Los espacios culturales y creativos que constituyen la plataforma para que la creatividad crezca (Landry, 2008), los espacios académicos que fomenten la creatividad (Florida, 2009), los establecimientos turísticos creativos (Richards \& Wilson, 2007) y la conectividad física y digital (Florida, 2009; Landry, 2010) favorecen el desarrollo de la creatividad en el sistema (Hui et al., 2005). 
Por tanto, las seis ciudades que ocupan los primeros puestos son Barcelona, Madrid, Santiago de Compostela, Valencia, Granada y Bilbao. Se tratan de seis destinos en los que las clases creativas, la tolerancia, calidad de vida y participación ciudadana y la oferta y el flujo turístico cultural es muy elevado, lo que contribuye a su posicionamiento en las primeras posiciones del creacity ambiental y, por tanto, a las primeras posiciones globales del índice global, hecho que ya contribuía al buen posicionamiento de los países en los índices propuestos por Florida y Tinagli (2004) y Hollanders y van Cruysen (2009).

Finalmente, reconocer que la matriz creativa del destino se convierte en un diagnóstico visual sobre el grado de desarrollo que presenta la creatividad en los sistemas turísticos urbanoculturales, estando basada en las once áreas que forman parte del índice Creacity. De esta forma, se conocen las ventajas y desventajas creativas de las ciudades turísticas, lo que permite confirmar, junto a los resultados presentados, la hipótesis planteada, siendo factible generar herramientas metodológicas eficaces para medir la creatividad de los destinos turísticos, obteniendo información útil que posibilite el diseño de estrategias enfocadas a mejorar su competitividad.

La necesidad de generar nuevas herramientas que evalúen la creatividad en los territorios sigue siendo un tema recurrente, que debe abordarse con cautela teniendo en cuenta las características únicas de cada uno de ellos. De cara al futuro, son muchas las posibles líneas de investigación que surgen cuando se trata de planificar y gestionar un destino turístico desde una perspectiva creativa. Como se ha podido ver en el desarrollo de la metodología propuesta, las áreas que forman las tres dimensiones del índice sintético Creacity están alimentadas por las fuentes estadísticas disponibles, lo que conlleva ciertas limitaciones a la hora de evaluar dichas dimensiones. En este caso, sería de gran utilidad la inclusión de indicadores más avanzados que proyecten, de una forma más veraz, la realidad del territorio analizado. A su vez, la inclusión de conceptos como la co-creación y el placemaking dentro del sistema de indicadores es una cuestión que requiere de la creación de más indicadores apoyados en la actividad turística para una óptima adaptación a la medición de la creatividad en destinos turísticos, además, de incluir aspectos centrados en la particularidad de dichos destinos. Además, sería necesario realizar una comparación directa entre el desarrollo turístico de los destinos urbano-culturales analizados y el posicionamiento que ocupan en el índice sintético Creacity, respondiendo a si los destinos turísticos más consolidados tienen mayor potencial para generar capital creativo (Romero-Padilla, Navarro-Jurado \& Malvárez-García, 2016). 
Ha quedado claro que los recursos endógenos de un destino son los principales factores a la hora de realizar una valoración de éste, pero existen redes de ciudades creativas, como la Creative Cities Network, que aportan dinamismo y vitalidad a sus integrantes, lo que conlleva a plantearse tener en consideración incorporar el análisis de redes sociales para evaluar cómo estos vínculos contribuyen a la creatividad. Por último, la operatividad de estos modelos debe ser exportada a los gestores turísticos a través de manuales de implementación que, a su vez, requieren de un seguimiento exhaustivo, lo que se podría traducir en DMOs especializadas a nivel internacional.

Declaración responsable: Las/os autoras/es declaran que no existe ningún conflicto de interés con relación a la publicación de este artículo. Las tareas se han distribuido de la siguiente manera: el artículo ha sido coordinado por Juan Ignacio Pulido-Fernández. La revisión bibliográfica corresponde a Jairo Casado-Montilla y José Antonio García Suárez, el sistema de indicadores ha sido diseñado por José Antonio García Suárez, el indicador sintético ha sido llevado a cabo por Beatriz Rodríguez-Díaz y el análisis, validación e interpretación de los resultados ha sido coordinado por José Antonio García Suárez y realizado por Juan Ignacio Pulido-Fernández, Beatriz Rodríguez-Díaz y Jairo Casado-Montilla. Finalmente, la redacción ha sido llevada a cabo por las/os autoras/es del artículo y su revisión final por Juan Ignacio PulidoFernández. 


\section{Referencias}

Akins, R., Tolson, H., \& Cole, B. (2005). Stability of response characteristics of a Delphi panel: Application of bootstrap data expansion. BMC Medical Research Methodology, 5(37).

Astigarraga, E. (2008). El Método Delphi. San Sebastián: Universidad de Deusto.

Atlantic Arc Cities (2012). Know cities in the Atlantic Arc. Retrieved from: hitps://charleslandry.com/about-charles-landry/recent-talks-and-projects/

Avella, J. (2016). Delphi Panels: Research design, procedures, advantages, and challenges. International Journal of Doctoral Studies, 11, 305-321.

Beier, L.S., Clavé, S.A., \& Vigier, H.P. (2020). Tolerance, Talent, and Attraction of Creative Workers in Tourism Destinations (Insights from the Province of Buenos Aires, Argentina). Tourism Planning \& Development, 18(1), 86-110. https://doi.org/10.1080/21568316.2020.1779799

Binkhorst, E. (2007). Creativity in tourism experiences: The case of Sitges. In G. Richards \& J. Wilson (Eds.), Tourism, creativity and development (pp. 125-144). New York, NY: Routledge.

Brown R.T. (1989) Creativity: What are we to measure? In J.A. Glover, R.R. Ronning, C.R. Reynolds (Eds.), Handbook of Creativity. Perspectives on Individual Differences (pp. 3-32). Boston: Springer. https://doi.org/10.1007/978-1-4757-5356-1_1

Csikszentmihalyi, M. (1996). Creativity: flow and the Psychology of Discovery and Invention. New York: Ed. Harper Perennial.

Clifton, N., Cooke, P., \& Hansen, H.K. (2013). Towards a reconciliation of the context-less with the space-less? The creative class across varieties of capitalism: New evidence from Sweden and the UK. Regional Studies, 47(2), 201-215.

Cooper, C., \& Hall, C. M. (2008). Contemporary Tourism: An International Approach. Routledge. de Bruin, A., \& Jelinčić, D.A. (2016). Toward extending creative tourism: participatory experience tourism. Tourism Review, 71(1), 57-66. https://doi.org/10.1108/TR-05-2015-0018

Florida, R. (2002). The rise of the creative class and how it's transforming work, leisure, comunity and everyday life. New York: Basic books.

Florida, R. (2009): Las ciudades creativas. Por qué donde vives puede ser la decisión más importante de tu vida. Barcelona: Paidós. 
Florida, R., Mellander, CH., \& King, K. (2015). The Global Creativity Index 2015. Toronto: Martin Prosperity Institute. Retrieved from http://martinprosperity.org/media/Global-Creativity-Index$\underline{2015 . p d f}$

Florida, R. \& Tinagli, I. (2004). Europe in the creative Age. Londres: Demos.

Fundación Orange (2012). Estudio Comparativo 2012 de los Servicios Públicos online en 40 Ayuntamientos españoles. Segunda oleada abril 2012. Retrieved from https://www. proyectosfundacionorange.es/docs/Estudio_Comparativo_Ayuntamientos_20 12.pdf

Gable, R.K., \& Wolf, J.W. (1993). Instrument development in the affective domain: Measuring attitudes and values in corporate and school setting. Boston: Kluwer Academic.

Glenn, J. C. (1999). Introducing to the futures research methodology series. In J.C. Glenn (Ed.), Futures research methodology. Washington D.C.: American Council for the United Nations University.

González, F., Romero, Y., Muro, I., Navarro, E., \& Gomis J.M. (2016). La localización de la clase creativa en ciudades turísticas. Un análisis a escala local del sistema urbano Mediterráneo español. Investigaciones turísticas, 11, 1-29.

Godet, M. (1996). Manuel de prospective stratégique. Paris: Dunod.

Goswami, A. (2014). Quantum creativity. UK: Hay House, Inc.

Grant, J.S., \& Davis, L.L. (1997). Selection and use of content expert for instrument development. Research in Nursing and Health, 20, 269-274.

Gunn, C.A. (1997). Vacationscape. Developing tourist areas. Washington: Routledge.

Hollanders, H., \& Van Cruysen, A. (2009). Design, Creativity and Innovation: a scoreboard approach. Pro Inno Europe, Innometrics. Maastricht: European Commission. Retrieved from https://citeseerx.ist.psu.edu/viewdoc/download?doi=10.1.1.924.793\&rep=rep1\&type=p df

Hui, D., Mok, F., Ngai, C., Wan-Kan, C., \& Yuen, C. (2005). A Study on Creativity Index. Home Affairs Bureau. Hong Kong: The Hong Kong Special Administrative Region Government.

Huidrobo, T. (2002). Una definición de creatividad a través del estudio de 24 autores seleccionados (Doctoral dissertation, Universidad Complutense de Madrid, Spain). Retrieved from https://eprints.ucm.es/id/eprint/4571/ 
Jager, A. K. A. (2009). Co-creation as a strategic element of tourism destination competitiveness. Paper presented at the third advances in tourism marketing conference: Marketing innovations for sustainable destinations: Operations, interactions, experiences. Bournemouth: Bournemouth University.

Jelinčić, D.A., \& Zuvela, A.(2012). Facing the challenge? Creative tourism in Croatia. Journal of Tourism Consumption and Practice, 4(2), 78-90.

Kaymack, E., \& Macaulay, J. (1984). The Delphi technique in the measurement of tourism market potential: the case of Nova Scotia. Tourism Management, 5(2), 87-101.

Landry, CH. (2008). The creative city, a toolkit for urban innovators. London: Earthscan.

Landry, CH. (2010). Índice de creatividad en Bilbao y Vizcaya. Bilbao: Fundación Bilbao Metropoli. Retrieved from http://www.bm30.es/Indice_Creatividad_Bizkaia.pdf

Leiper, N. (1979). The framework of tourism. Annals of Tourism Research, 6(4), 390-407.

Leiper, N. (1990). Tourist Attraction System. Annals of Tourism Research, 17, 367-384.

Lew, A.A. (2017). Tourism planning and place making: place-making or placemaking? Tourism Geographies, 19(3), 448-466. https://doi.org/10.1080/14616688.2017.1282007

Lucia, M. Della, \& Trunfio, M. (2018). The role of the private actor in cultural regeneration: Hybridizing cultural heritage with creativity in the city. Cities, $82,35-44$

Luque, M., Pérez-Moreno, S., Robles, J. A., \& Rodríguez, B. (2017). Measuring Child and Maternal Health in Developing Countries: A Proposal of New Hybrid MDG Composite Indices. Applied Research in Quality of Life, 12(3), 737-758.

Lugosi, P., \& Walls, A. R. (2013). Researching destination experiences: Themes, perspectives and challenges. Journal of Destination Marketing \& Management, 2(2), 51-58.

Mackinnon, D.W. (1970). Creativity: a multifaceted phenomenon. In J.D. Roslansky (Ed.), Creativity: a discussion at the Nobel Conference (pp. 17-32). Amsterdam: North-Holland.

Ministerio de Educación, Cultura y Deporte (2015). Anuario de Estadísticas culturales 2015. Spain.

Monreal, C. (2000). ¿ Qué es la creatividad? Madrid: Biblioteca Nueva. 
Mooney, R.L. (1963). A conceptual model for integrating four approaches to the identification of creative talent. In C.W. Taylor y F. Barron (Eds.): Scientific creativity: its recognition and development (pp. 331-340). New York: Wiley.

Moreno, S., \& Picazo, P. (2012). Difusión de la investigación científica en revistas de turismo realizadas por instituciones españolas. Revista de Análisis Turístico, 14, 33-52.

Orwig, W., Diez, I., Vannini, P., Beaty, R., \& Sepulcre, J. (2021). Creative connections: Computational semantic distance captures individual creativity and resting-state functional connectivity. Journal of Cognitive Neuroscience, 33(3), 499-509.

Pena, J. B. (1977). Problemas de la medición del bienestar y conceptos afines. Una aplicación al caso español. Madrid: INE.

Pesquera, M.A., Casares-Hontañon, P., Coto-Millán, P., \& López De Sabando, V.I. (2010). Innovación empresarial, clase creativa y desarrollo económico en España. Valencia: Ed. Tirant Lo Blanch.

Project for Public Spaces (PPS). (2004). What if we built our cities around places? Project for Public Spaces Non-Profit Organization. Retrieved from https://www.pps.org/article/greatcitiesinitiative

Pulido-Fernández, J.I. (2007). El turismo en el desarrollo económico de los parques naturales andaluces. Un análisis Delphi de los principales déficit. Revista de Estudios Empresariales, segunda época, 1, 110-137.

Pulido-Fernández, J.I., Cárdenas-García, P.J., \& Carrillo-Hidalgo, I. (2016). Trip Cultural Activities and Tourism Expenditure in Emerging Urban-cultural Destinations. International Journal of Tourism Research, 18(4), 286-296.

Pulido-Fernández, J. I., \& López-Sánchez, Y. (2016). La cadena de valor del destino como herramienta innovadora para el análisis de la sostenibilidad de las políticas turísticas. El caso de España. Innovar, 26(59), 155-176. https://doi.org/10.15446/innovar.v26n59.54369

Ramírez-Alujas, A. (2014). Gobierno Abierto. Eunomía. Revista en Cultura de la Legalidad, 2, 201-216.

Richards, G. (2010). Tourism development trajectories - From culture to creativity? Tourism \& Management Studies, 6, 9-15. 
Richards, G. (2019). Creative tourism: Opportunities for smaller places? Tourism \& Management Studies, 15(SI), 7-10.

Richards, G., \& Marques, L. (2012). Exploring creative tourism: Editors introduction. Journal of Tourism Consumption and Practice, 4(2), 1-11.

Richards, G. \& Raymond, C. (2000). Creative tourism. ATLAS News, 23, 16-20.

Richards, G., \& Wilson, J. (2006). Developing creativity in tourist experiences: A solution to the serial reproduction of culture? Tourism Management, 27(6), 1209-1223.

Richards, G., Wisansing, J., \& Paschinger, E. (2019). Creating creative tourism toolkit (2nd ed.). Bangkok: DASTA.

Rhodes, M. (1961). An analysis of creativity. Phi Delta Kappan, 42, 305-310.

Rodríguez, J. A. (2012). Medición del bienestar social en las regiones de Chile en 2007. V Premio José Luis Sampedro, XIV Reunión de Economía Mundial (XIV REM), Jaén.

Romero-Padilla, Y., Navarro-Jurado, E., \& Malvárez-García, G. (2016). The potential of international coastal mass tourism destinations to generate creative capital. Journal of Sustainable Tourism, 24(4), 574-593.

Romero-Padilla, Y., Navarro-Jurado, E. \& Romero-Martínez, J.M. (2020). Destinos turísticos y capital creativo: el caso de la costa del sol en el sur de España. Revista de Geografía Norte Grande, 77, 339-365.

Sancho, A. (1998). Introducción al turismo. Madrid: UNWTO.

Somarriba, N. (2008). Aproximación a la medición de la calidad de vida en la Unión Europea. Tesis doctoral. Valladolid: Universidad de Valladolid.

Somarriba, N. \& PENA, B. (2008). Aproximación a un indicador regional y nacional de los objetivos de Lisboa a partir de distancia P2. Estudios Económicos de Desarrollo Regional, 2, 8394.

Somarriba, N., \& Pena, B. (2009a). Synthetic Indicadores of Quality of Life in Europe. Social Indicators Research, 96, 83-96.

Somarriba, N., \& Pena, B. (2009b). La medición de la calidad de vida en Europa, el papel de la información subjetiva. Estudios de Economía Aplicada, 27(2), 373-396. 
Transparency Internacional Spain (2012). Índice de transparencia de los ayuntamientos 2012. Spain.

UNESCO (2004). Red de ciudades creativas. Retrieved from http://www.unesco.org/new/fileadmin/MULTIMEDIA/HQ/CLT/pdf/Creative_cities_bro chure_es.pdf

UNESCO (2006). Towards Sustainable Strategies for Creative Tourism (Informe de discusión de la reunión de planificación para 2008 conferencia internacional sobre turismo creativo). Santa Fe: Nuevo México.

Zabelina, D. L. (2018). Attention and creativity. In R. E. Jung \& O. Vartanian (Eds.), The Cambridge handbook of the neuroscience of creativity (p. 161-179). Cambridge: Cambridge University Press.

Zabelina, D. L., Hechtman, L. A., Sporta, A., Grunewald, K., \& Beeman, M. (2020). Brain activity sensitive to visual congruency effects relates to divergent thinking. Brain and Cognition, $135,103587$.

Zarzosa, P. (1996). Aproximación a la medición del bienestar social. Valladolid: Universidad de Valladolid.

Zarzosa, P. (2009). Estimación de la pobreza en las comunidades autónomas españolas, mediante la distancia $\mathrm{DP}_{2}$. Estudios de Economía Aplicada, 27(2), 397-416. 